\title{
Cavin-1 and Caveolin-1 are both required to support cell proliferation, migration and anchorage-independent cell growth in rhabdomyosarcoma
}

\author{
Fiorella Faggi ${ }^{1,2}$, Nicola Chiarelli ${ }^{1}$, Marina Colombi ${ }^{1}$, Stefania Mitola ${ }^{1}$, Roberto Ronca ${ }^{1}$, Luca Madaro ${ }^{2,3}$, \\ Marina Bouche ${ }^{2,3}$, Pietro L Poliani ${ }^{1}$, Marika Vezzoli ${ }^{1}$, Francesca Longhena ${ }^{1}$, Eugenio Monti ${ }^{1}$, Barbara Salani ${ }^{4}$, \\ Davide Maggi ${ }^{4}$, Charles Keller ${ }^{5,6}$ and Alessandro Fanzani ${ }^{1,2}$
}

\begin{abstract}
Rhabdomyosarcoma (RMS) is a childhood soft tissue tumor with broad expression of markers that are typically found in skeletal muscle. Cavin-1 is a recently discovered protein actively cooperating with Caveolin-1 (Cav-1) in the morphogenesis of caveolae and whose role in cancer is drawing increasing attention. Using a combined in silico and in vitro analysis here we show that Cavin-1 is expressed in myogenic RMS tumors as well as in human and primary mouse RMS cultures, exhibiting a broad subcellular localization, ranging from nuclei and cytosol to plasma membrane. In particular, the coexpression and plasma membrane interaction between Cavin-1 and Cav-1 characterized the proliferation of human and mouse RMS cell cultures, while a downregulation of their expression levels was observed during the myogenic differentiation. Knockdown of Cavin-1 or Cav-1 in the human RD and RH30 cells led to impairment of cell proliferation and migration. Moreover, loss of Cavin-1 in RD cells impaired the anchorage-independent cell growth in soft agar. While the loss of Cavin-1 did not affect the Cav-1 protein levels in RMS cells, Cav-1 overexpression and knockdown triggered a rise or depletion of Cavin-1 protein levels in RD cells, respectively, in turn reflecting on increased or decreased cell proliferation, migration and anchorage-independent cell growth. Collectively, these data indicate that the interaction between Cavin-1 and Cav-1 underlies the cell growth and migration in myogenic tumors.
\end{abstract}

Laboratory Investigation (2015) 95, 585-602; doi:10.1038/labinvest.2015.45; published online 30 March 2015

Rhabdomyosarcoma (RMS) is a childhood soft tissue sarcoma exhibiting broad expression of skeletal muscle markers, ${ }^{1-3}$ such as Pax7, MyoD, Myogenin, desmin and muscle-specific actin. ${ }^{4,5}$ Cells of origin in RMS may be different muscular and non-muscular cell precursors, ${ }^{6-8}$ such as muscle satellite cells (SCs), ${ }^{9-11}$ and myoblasts $9,10,12-14$ or adipocytes, ${ }^{15}$ which are responsible of two major histological subtypes known as embryonal (ERMS) and alveolar (ARMS). The most common ERMS variant arises in children usually $<5$ years on distinct body sites, such as head, neck and genitourinary regions, while ARMS typically arises in the muscular limb extremities of adolescents and is characterized by poorer prognosis. ${ }^{16}$ The genomic landscape causative of ERMS is characterized by a number of genetic lesions and/or somatic mutations that deliberately sustain the activity of different receptors, such as
IGF1R, FGFR4 and Patched, ${ }^{17-21}$ and related downstream pathways (i.e., RAS/ERK, PI3K/AKT and Sonic Hedgehog signaling). ${ }^{11,22}$ In addition, defects in tumor suppressors (i.e., p53), ${ }^{23}$ cell cycle regulatory genes (i.e., N-Myc, Rb1) (1,24 $^{21}$ and structural proteins involved in muscular integrity (i.e., dystrophin, alpha-sarcoglycan and dysferlin) have been reported. ${ }^{25-30}$ Conversely, ARMS is dominated by the presence of specific chromosomal translocations leading to expression of the fused Pax3-Foxo1 and Pax7-Foxo1 factors, that driving in a cell cycle manner the transcription of several genes normally restricted to the embryonal development favor tumor initiation in some muscle precursors. ${ }^{31-36}$

A number of important cellular processes, such as endocytosis, cholesterol homeostasis and signal transduction,

\footnotetext{
${ }^{1}$ Department of Molecular and Translational Medicine, University of Brescia, Brescia, Italy; ${ }^{2}$ Interuniversity Institute of Myology (IIM), Rome, Italy; ${ }^{3}$ Unit of Histology and IIM, Sapienza University, DAHFMO, Rome, Italy; ${ }^{4}$ Department of Endocrinology and Medicine, University of Genoa, Genoa, Italy; ${ }^{5}$ Department of Pediatrics, Oregon Health Science University, Portland, OR, USA and ${ }^{6}$ Children's Cancer Therapy Development Institute, Portland, OR, USA Correspondence: Dr A Fanzani, PhD, Department of Molecular and Translational Medicine University of Brescia, Viale Europa 11, Brescia 25123, Italy. E-mail: alessandro.fanzani@unibs.it
} 
takes place in small invaginations of the plasma membrane known as caveolae, ${ }^{37}$ specialized microdomains whose morphogenesis and function depend on the complex network established between two protein families known as Caveolins (Cav-1, Cav-2 and Cav-3) $)^{38-40}$ and Cavins (Cavin-1, -2, -3 and -4$).^{41-44}$ In particular, deficiency of either Cav- $1^{45}$ or Cavin- $1^{46-48}$ has been reported to cause global loss of caveolae in different tissues. Cav-1 is a scaffolding protein that forms supramolecular complexes anchored to the inner leaflet of the plasma membrane and has been historically reported to be sufficient for de novo formation of caveolae in both caveolaedeficient cells ${ }^{49}$ and bacteriae. ${ }^{50}$ Cavin-1 was instead recently discovered as a soluble protein stabilizing Cav-1 oligomers and presumably facilitating their membrane insertion underlying the generation of the characteristic caveolar profile. ${ }^{46,47,51}$ Altered expression levels and gene mutations affecting stability and/or localization of these proteins have been widely reported to be causative of various diseases, ranging from lung diseases and muscular dystrophies to cancer. In RMS, we have previously shown that Cav-1 expression is often associated to a cell status of scarce differentiation. ${ }^{52,53}$ More recently, we have also shown that high Cav-1 protein levels enhance RMS tumor growth and chemoresistance, whereas Cav-1 depletion limits cell proliferation, migration and invasion as well as sensitizes RMS cells to chemotherapy drug-induced apoptosis. ${ }^{54}$ Here we have used a combined in silico and in vitro approach to address the question of whether Cavin-1 may be expressed and have a role in RMS. To this purpose, we have used human RMS cell lines as well as primary mouse tumor cultures established from transgenic mouse models faithfully recapitulating the onset and progression of RMS. Our findings unveil that Cavin-1, forming plasma membrane complexes with Cav-1, contributes in sustaining proliferation, migration and anchorage-independent growth of RMS cells.

\section{MATERIALS AND METHODS}

All reagents were from Sigma-Aldrich (Milan, Italy), unless otherwise stated. Cell culture materials were purchased from Jet-Biofil (Carlo Erba Reagents-Dasit Group, Cornaredo, Italy).

\section{Microarray Gene Expression Data Analysis}

All analyses of microarray gene expression data were performed with the Partek Genomics Suite software version 6.6 (Partek, St Louis, MO, USA). Briefly, the microarray raw data set with the accession number GSE22520 ${ }^{10}$ deposited in the NCBI Gene Expression Omnibus database were reprocessed by background correction, normalization and summarization of probe intensities using the robust multiarray average analysis to determine the specific hybridizing signal for each probe set. After background correction, the data expression of each probe was corrected for perfect match intensity and was transformed in base-2 logarithm. ${ }^{55}$ Quality control was performed by investigating principal component analysis to detect grouping patterns in the samples and to identify the outliers and evaluate whether batch effect significantly affected the data. To detect differentially expressed genes (DEGs) between mouse ARMS/ERMS vs normal muscle samples, a one-way analysis of variance (ANOVA) was performed. To assess significant differences in the gene expression profile in all groups, we selected the genes that had more than a 2.0 -fold change $(\mid \mathrm{FCl} \geq 2.0)$ and $P$-values $<0.05$. Multiple testing correction was applied to control the false-discovery rate using the Benjamini-Hochberg procedure. All corrected $P$-values $<0.05$ were considered significant.

\section{Histological and Immunofluorescence Analyses}

Muscle cryosections were fixed in $4 \%$ paraformaldehyde (PFA) on ice. Immunofluorescence analysis of cryosections was performed as previously described. ${ }^{56}$ Nuclei were counterstained with Hoechst 33342 (Fluka, Sigma-Aldrich) or with TO-PRO-3 (Invitrogen, Life Technologies, Monza, Italy), and the samples were analyzed under an epifluorescence Zeiss Axioskop 2 Plus microscope (Carl Zeiss, Oberkochen, Germany) or a Leica Leitz DMRB microscope fitted with a DFC300FX camera (Leica, Wetzlar, Germany).

\section{Muscle Satellite Cell Cultures and Tumor Cultures}

Primary mouse SCs were prepared from 1-2-week postnatal mouse limbs as described previously. ${ }^{56}$ The cells were grown in Dulbecco's modified Eagle's medium (DMEM) supplemented with $20 \%$ horse serum (HS) and 5\% chick embryo extract (EE). To induce differentiation, the cells were shifted to DMEM supplemented with 5\% HS and $1.25 \%$ EE for 35 days. Human embryonal RD cells were purchased from the European Collection of Cell Cultures. RD cells harbor activating or inactivating RAS and p53 mutations, respectively. ${ }^{57-59}$ Human RD12 and RD18 clonal cell lines, provided by PL Lollini (University of Bologna, Italy), were derived by random cloning of the human RD cell line. ${ }^{60,61}$ Human RH30 cells have a tetraploid karyotype and harbor both the Pax3Foxol signature derived from the $t(2 ; 13)$ translocation $^{62}$ and p53-inactivating mutations. ${ }^{59}$ The primary mouse ERMS and ARMS cultures, namely, U57810 and U23674, respectively, have been derived from transgenic mice harboring either loss of p53 or concomitant loss of p53 and knock-in of Pax3Foxo1 in Myf6-positive differentiating myoblasts, respectively. ${ }^{10,13}$ Tumor cells were routinely maintained under standard conditions $\left(37^{\circ} \mathrm{C}\right.$ and $5 \% \mathrm{CO}_{2}$ in humidified incubator) in a growth medium (GM), composed of highglucose DMEM supplemented with $10 \%$ fetal bovine serum (FBS) and $100 \mu \mathrm{g} / \mathrm{ml}$ penicillin-streptomycin antibiotics, in the presence of 1\% L-glutamine (only for RH30 and U23674 cells). To induce myodifferentiation, $80 \%$ confluent cells were switched to a differentiating medium (DM), composed of DMEM supplemented with $2 \%$ HS. Cells received the chemical PD098059 $(10 \mu \mathrm{M}$, dissolved in dimethylsulfoxide vehicle), a synthetic upstream inhibitor of the RAS/ERK cascade, the pan-phosphatase inhibitor $\mathrm{Na}_{3} \mathrm{VO}_{4}$ 
(20 $\mu \mathrm{M}$, dissolved in water) and the chemotherapy drug doxorubicin $(0.15 \mathrm{ng} / \mathrm{ml}$, dissolved in water $)$.

\section{RNA Isolation and Semi-Quantitative RT-PCR Analysis}

Total RNA was isolated using a Tri-reagent kit and treated with DNA-free DNase (Promega, Madison, WI, USA). RNA
$(2 \mu \mathrm{g})$ was reverse transcribed in the presence of 400 Units of Moloney murine leukemia virus reverse transcriptase enzyme (Promega) and the obtained cDNA template was used for PCR analysis using specific forward and reverse primers $(250 \mathrm{nM})$ annealing to both human and mouse sequences. In particular, a 424-bp-long Cavin-1 fragment was amplified

a
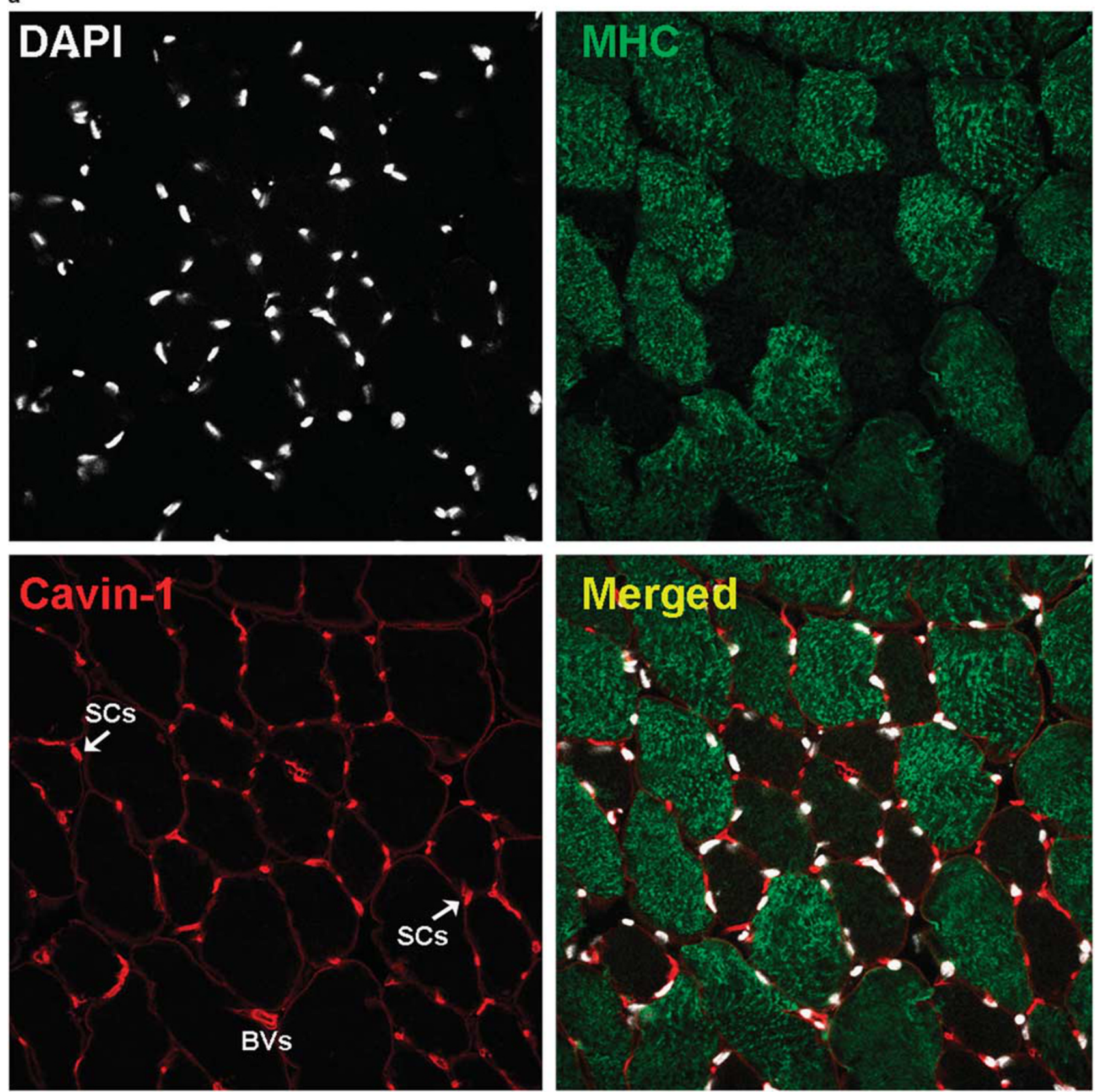

Figure 1 Analysis of Cavin-1 in skeletal muscle and in muscle satellite cells (SCs). (a) Immunofluorescence analysis was carried out on mouse cryosections from tibialis anterior skeletal muscle to analyze distribution of Cavin-1 (red), using MHC (green) as marker of differentiated myofibers. The counterstaining with DAPI reactive was used to visualize cell nuclei. BVs stands for blood vessels. (b) Purified SCs were seeded in $60 \mathrm{~mm}$ dishes (at a density of $12 \times 10^{4}$ cells) and cultured in GM until confluence, followed by incubation in DM. After $72 \mathrm{~h}$ in GM or DM, cells were harvested and protein homogenates subjected to centrifugation for separating membranous from soluble fractions. Equal amounts of proteins were then western blotted for Cavin-1, Cav-3 and tubulin. Protein bands were quantified by densitometry after normalization with respect to tubulin $(n=3)$. ${ }^{* *} P<0.001 ;{ }^{* * *} P<0.0001$. 


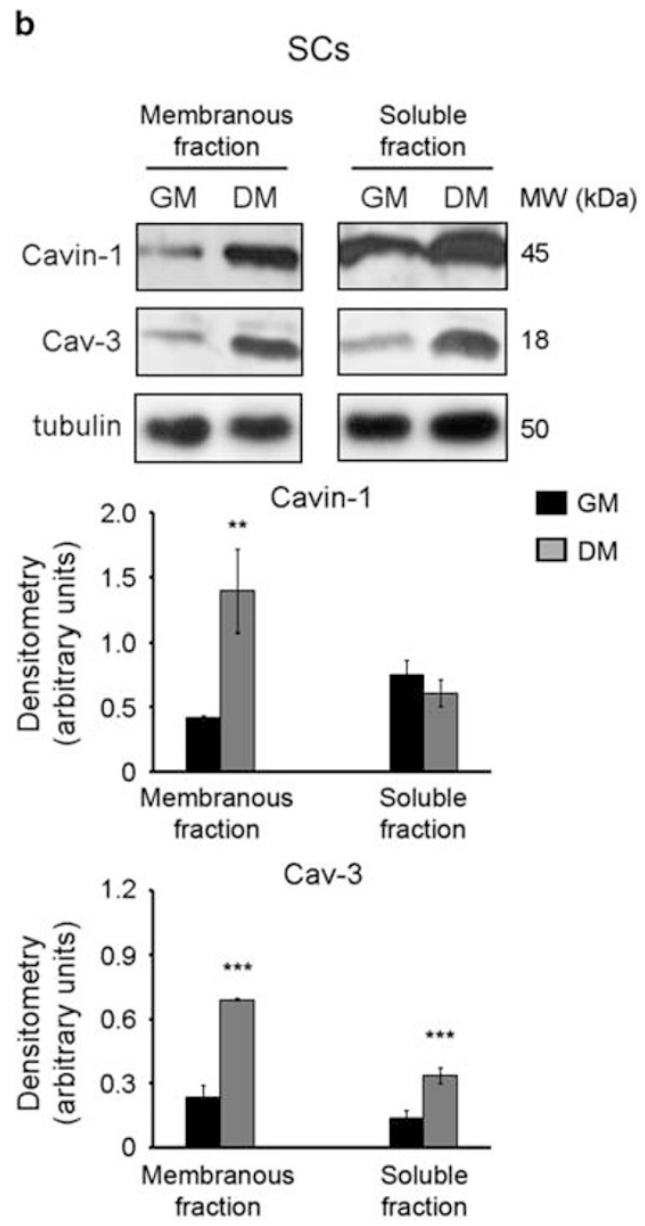

Figure 1 Continued.

with $5^{\prime}$-ATCAAGAAGCTGGAGGTCAACGAG- ${ }^{\prime}$ and $5^{\prime}$-TC TCAGGTTTTCCTTGGTCTTGA-3' primers, a 103-bp-long Cav-1 fragment with $5^{\prime}$-AACCGCGACCCTAAACACCT-3' and $5^{\prime}$-CCTTCCAAATGCCGTCAAAA-3' primers and a 267-bp-long Gapdh fragment with 5'-GGTGCTGAGTATGT CGTGGAGTC- $3^{\prime}$ and $5^{\prime}$-GGACTGTGGTCATGAGCCCTT CC- $3^{\prime}$ primers.

\section{Plasmids and Transfection}

Knockdown constructs were purchased from Tema-Ricerca/ Origene (Castenaso, Italy) in pRS backbone: shCavin-1 \#1 (clone TR310045A-TI340173, 5'-ATGATCTACCAGGATG AAGTGAAGCTGCC- $3^{\prime}$ ); shCavin-1 \#2 (clone TR310045BTI340174, 5'-CGCAAGGTCAGCGTCAACGTGAAGACCGT-3'); shCavin-1 \#3 (clone TR310045C-TI340175, 5'-CACCTTCC ACGTCAAGAAGATCCGCGAGG-3'). As negative control, pRS-puro vector harboring the off-target sequence (clone TR30012， 5'-GCACTACCAGAGCTAACTCAGATAGTACT $\left.-3^{\prime}\right)$ was used. Cav-1 overexpression and knockdown were obtained as previously described in Faggi et al. ${ }^{54}$ Cells were stably transfected using Transit-LT1 reagent (Tema-Ricerca) according to the manufacturer's protocol. After antibiotic selection, the experiments produced similar results in all the selected clones.

\section{Antibodies}

The following primary antibodies were used: rabbit antiCavin-1 (AbCam, Cambridge, UK, 1:3000 dilution) for immunoblotting and immunofluorescence analyses; rabbit anti-Cavin-1 (ThermoScientific, Waltham, MA, USA) for immunoprecipitation assay; rabbit anti-Cav-1 (Santa Cruz Biotechnology, Dallas, TX, USA, 1:1000 dilution); mouse anti-Cav-1 (Zymed-Life Technologies, Monza, Italy, 1:100 dilution); mouse anti-MHC (Santa Cruz Biotechnology, 1:1000 dilution); mouse anti-Cav-2 (BD, Buccinasco, Italy, 1:1000 dilution); mouse anti-Cav-3 (BD, 1:1000 dilution); mouse anti-total and -phosphorylated ERK1/2 (Tyr204) (Santa Cruz Biotechnology, 1:1000 dilution); mouse antialpha-tubulin (Sigma-Aldrich, 1:10 000 dilution).

\section{Immunoblotting and Immuneprecipitation Analyses}

Protein concentration was calculated by Bradford reagent assay. Equal amounts of protein samples were separated by SDS-PAGE under reducing conditions and transferred to polyvinylidine fluoride membranes. Incubation with specific primary antibodies was followed by horseradish peroxidaseconjugated secondary antibodies, including goat anti-mouse IgG (Santa Cruz Biotechnology) and donkey anti-rabbit IgG from Thermo Scientific-Pierce, Erembodegem, Belgium), and the resulting immune complexes were visualized using enhanced chemiluminescence reagent (GeneSpin, Milan, Italy). Immune-reactive bands were quantified using densitometric analyses (Software Gel Pro Analyzer, version 4). For detection of Cavin-1, myosin heavy chain (MHC) and tubulin, total homogenates were prepared by harvesting the cells in cold RIPA lysis buffer, composed of $20 \mathrm{mM}$ Tris- $\mathrm{HCl}$ ( $\mathrm{pH}$ 7.6), 1\% Nonidet P40, 0.5\% sodium deoxycholate, $0.1 \%$ SDS, $50 \mathrm{mM} \mathrm{NaCl}$, and a cocktail of protease inhibitors (Roche, Monza, Italy) plus phosphatase inhibitors ( $1 \mathrm{mM}$ $\mathrm{Na}_{3} \mathrm{VO}_{4}$ and $4 \mathrm{mM} \mathrm{NaF}$ ). Total homogenates were then centrifuged at $12000 \mathrm{~g}$ for $10 \mathrm{~min}$ at $4{ }^{\circ} \mathrm{C}$. For detection of Caveolins, the Triton-insoluble membranous fractions were obtained by harvesting the cells in a cold Triton buffer, composed of $10 \mathrm{mM}$ Tris- $\mathrm{HCl}(\mathrm{pH} 8.0), 1 \%$ Triton X-100, $5 \mathrm{mM}$ EDTA, $150 \mathrm{mM} \mathrm{NaCl}$ and a cocktail of protease inhibitors plus phosphatase inhibitors, followed by centrifugation $\left(15000 \mathrm{~g}\right.$ for $15 \mathrm{~min}$ at $\left.4^{\circ} \mathrm{C}\right)$.

For immunoprecipitation analysis, the cells were lysed in a buffer composed of $50 \mathrm{mM}$ Tris- $\mathrm{HCl}$ buffer ( $\mathrm{pH}$ 7.4), containing $150 \mathrm{mM} \mathrm{NaCl}, 1 \%$ Triton X-100 and a cocktail of protease and phosphatase inhibitors, followed by incubation for $20 \mathrm{~min}$ at $4{ }^{\circ} \mathrm{C}$. After centrifugation $(10 \mathrm{~min}, 11500 \mathrm{~g}$ at $4{ }^{\circ} \mathrm{C}$ ), supernatants were pre-cleared with protein $\mathrm{G}-$ Sepharose ( $20 \mu \mathrm{l} / \mathrm{sample}$, GE Healthcare, Fairfield, CT, USA) for $1 \mathrm{~h}$. Cell extracts (1 mg aliquots) were incubated overnight with bland agitation at $4{ }^{\circ} \mathrm{C}$ with rabbit polyclonal anti-Cav-1 
- ARMS $(n=14)$

- ERMS $(n=7)$

- Skeletal muscle $(n=4)$

Cavin-1

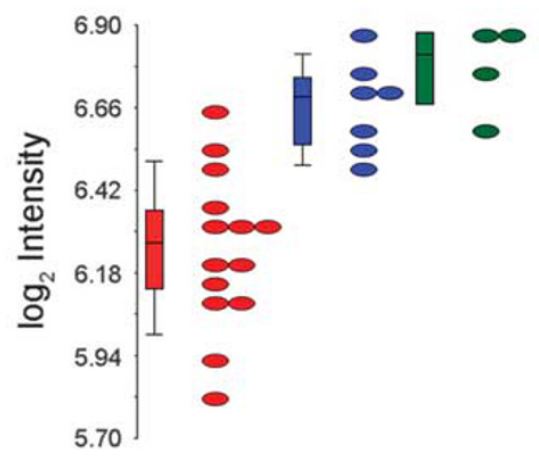

Cav-2

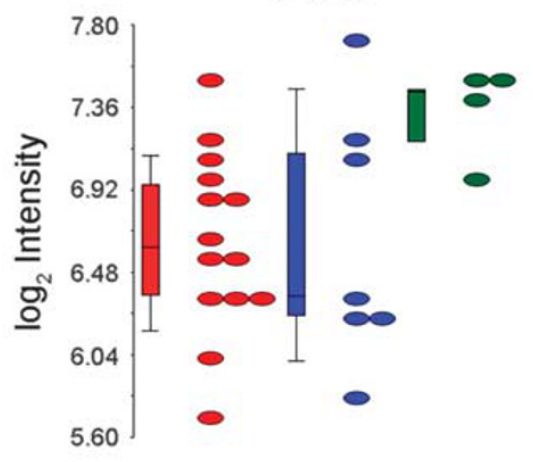

Cav-1

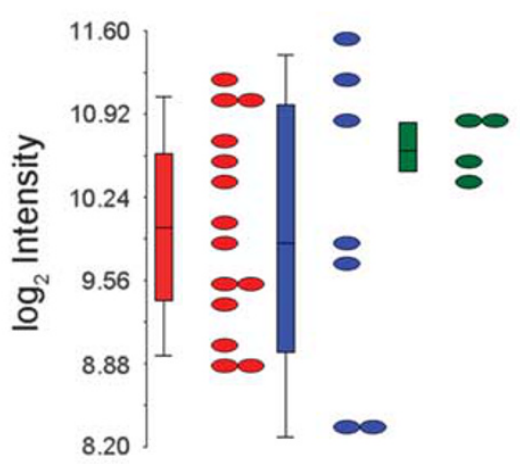

Cav-3

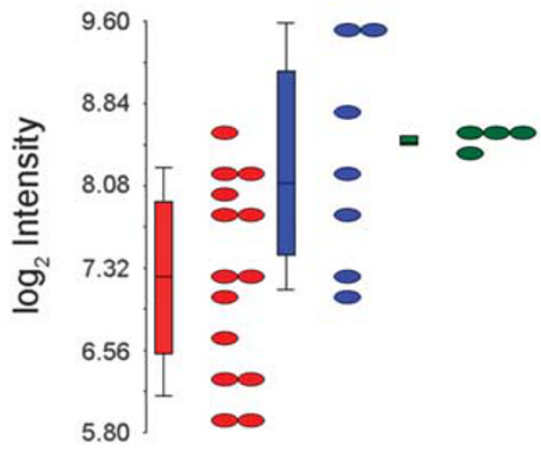

b

Venn Diagramm

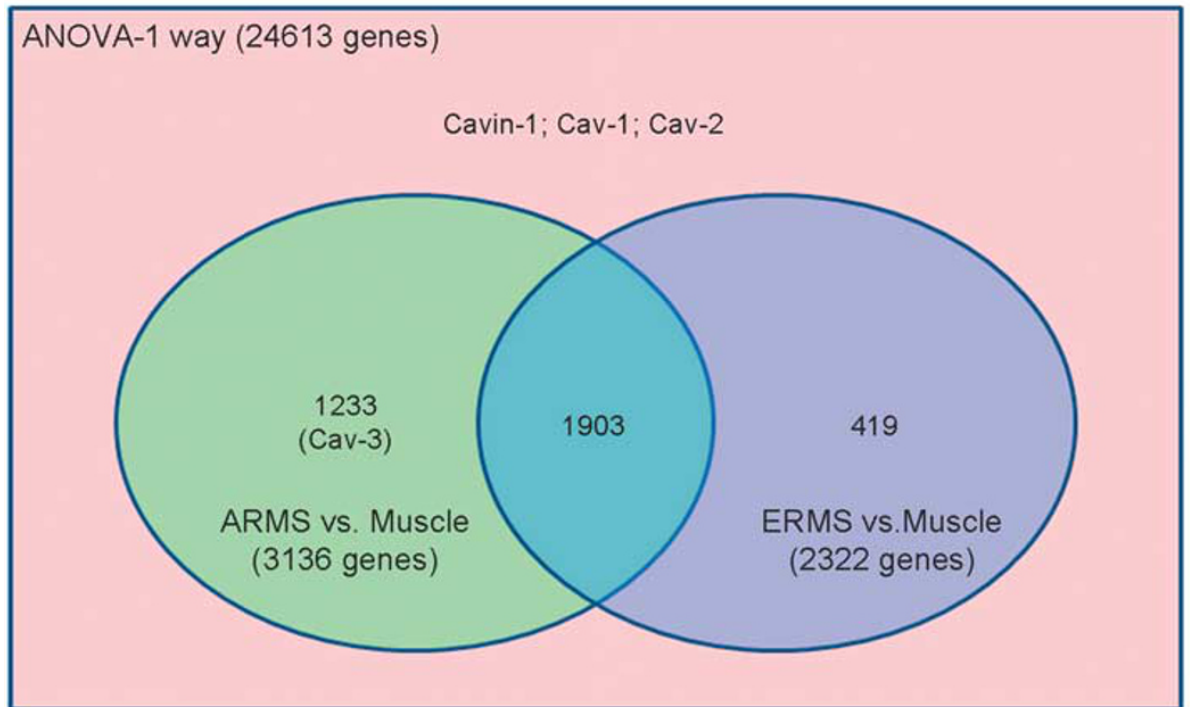

Figure 2 In silico analysis of Cavin-1 and Caveolins transcriptional levels in mouse RMS tumors. (a) Representative dot plot of the mRNA expression levels of Cavin-1, Cav-1, Cav-2 and Cav-3 genes in ARMS, ERMS and normal muscle samples. In the plot, each dot is a sample of the original data. The $y$-axis represents the $\log _{2}$-normalized intensity of the gene and the $x$-axis represents the different types of samples. Bars represent the average \pm s.e.m. (b) Venn diagram depicts the overlap between differentially expressed transcripts ( $\geq 2$-fold expression; $P<0.05$ ) in ARMS or ERMS vs normal muscle. 
( $5 \mu \mathrm{l} /$ sample, Santa Cruz Biotechnology) or rabbit anti-Cavin1 (10 $\mu \mathrm{l} / \mathrm{sample}$, ThermoScientific). Immune complexes were then recovered on protein G-Sepharose (1 h with bland agitation at $\left.4^{\circ} \mathrm{C}\right)$, centrifuged $(1 \mathrm{~min}, 14000 \mathrm{~g}$ ) and washed four times with lysis buffer and twice with the same buffer without Triton X-100. Proteins were then analyzed on nonreducing SDS-12\% PAGE followed by immunoblotting with anti-Cavin-1 and anti-Cav-1 antibodies. The enhanced chemiluminescence technique (Genespin) was used for detection. As positive control, $30 \mu \mathrm{g}$ of total homogenates was loaded, whereas $30 \mu \mathrm{g}$ of pre-cleared sample was loaded as negative control. a
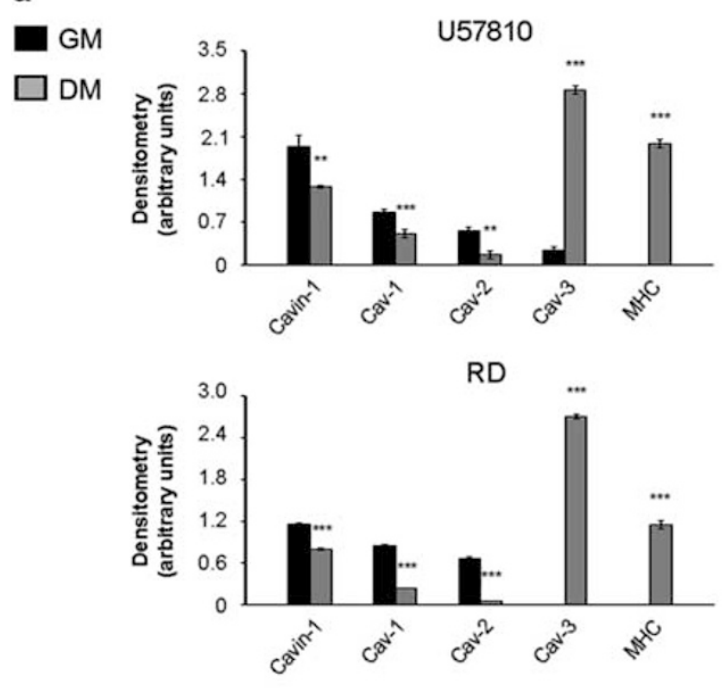

RD18
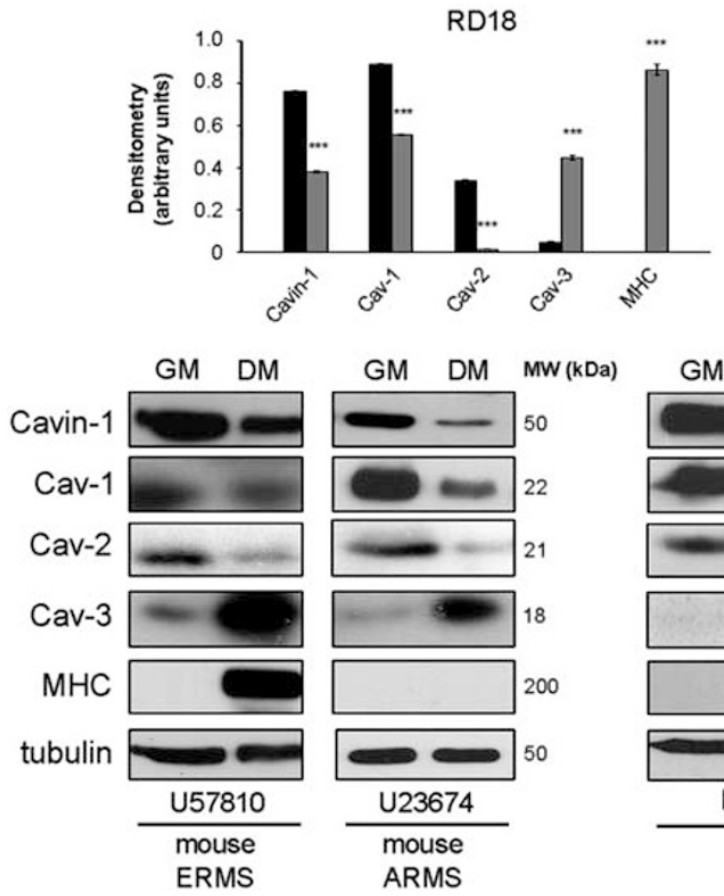
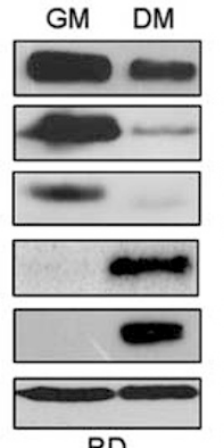

RD

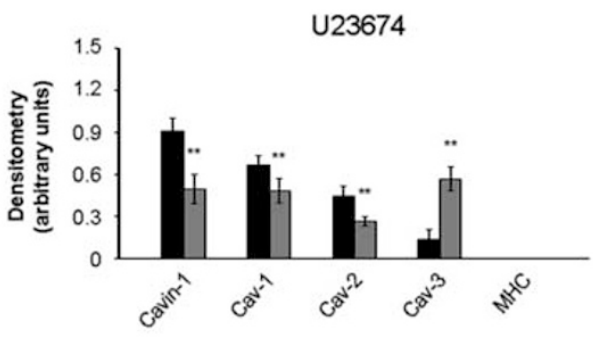

RD12

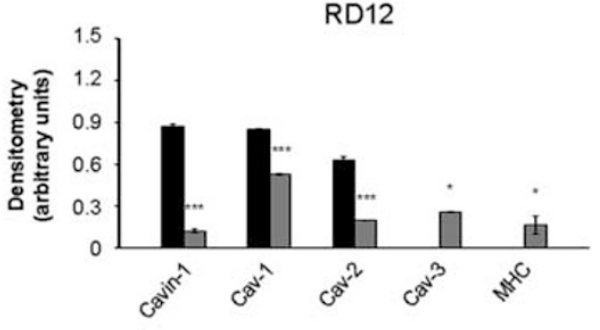

$\mathrm{RH} 30$

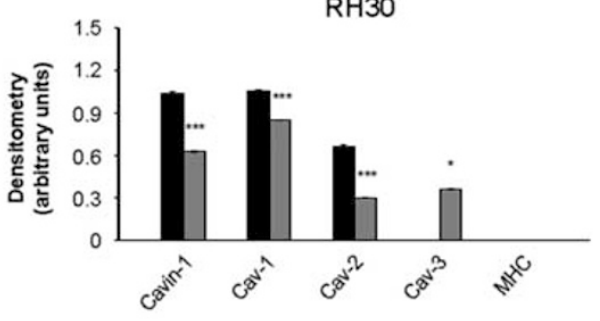

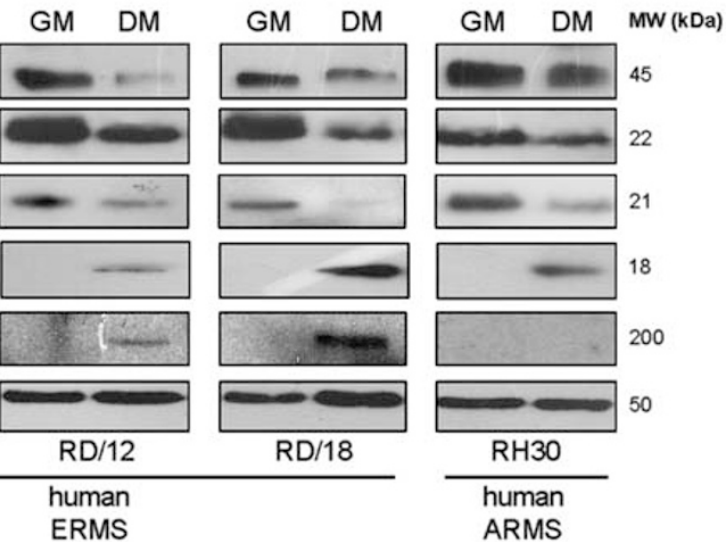

Figure 3 In vitro analysis of Cavin-1 and Caveolins protein levels in human RMS lines and primary mouse tumor cultures. (a) Cavin-1 and Caveolins protein levels were analyzed in two primary mouse tumor cultures (embryonal U57810 and alveolar U23674) established from conditional transgenic mice and four human RMS cell lines (embryonal RD, RD12, RD18 and alveolar RH30). Cells were seeded in 60 mm dishes (at a density of $12 \times 10^{4}$ cells) and cultured in GM until confluence, followed by incubation in DM. After $72 \mathrm{~h}$ in GM or DM, cells were harvested and protein homogenates western blotted for Cavin-1, Caveolins, MHC and tubulin. Protein bands were quantified by densitometry after normalization with respect to tubulin $(n=3)$. ${ }^{*} P<0.05$; ${ }^{* *} P<0.001$; ${ }^{* * *} P<0.0001$. (b) Confocal microscopy analysis was employed to analyze the distribution of Cavin-1, Cav-2 and Cav-3 in RMS cells. Human RD cells cultured in GM for $72 \mathrm{~h}$ were fixed, permeabilized and immunostained with antibodies against Cavin-1, Cav-1 and Cav-2 followed by anti-rabbit and anti-mouse Cy3, respectively. Alternatively, confluent RD cells were cultured in DM for $72 \mathrm{~h}$ and then fixed, permeabilized and immunostained with antibodies against Cavin-1 and Cav-3 followed by anti-rabbit Alexa488 and anti-mouse Cy3, respectively. 
b
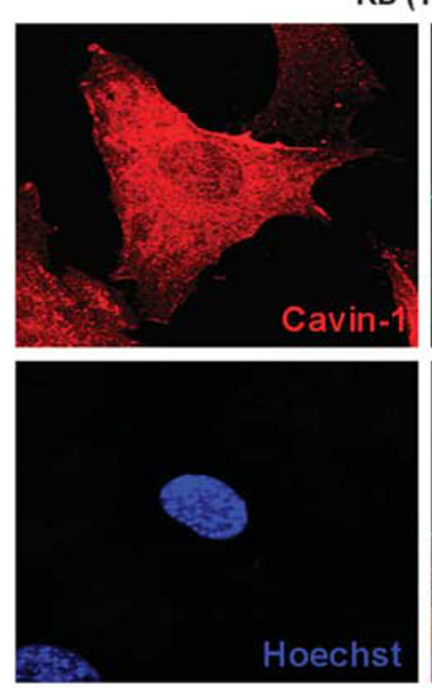

RD (100x)
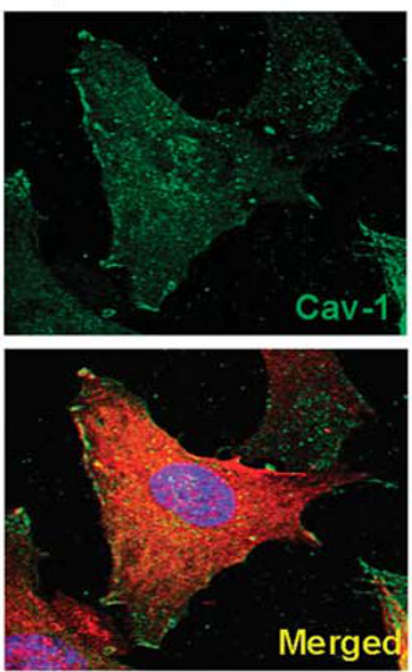

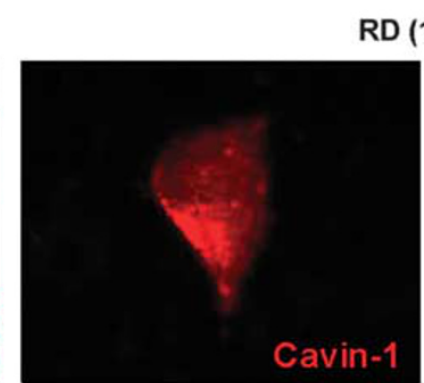

RD (100x)
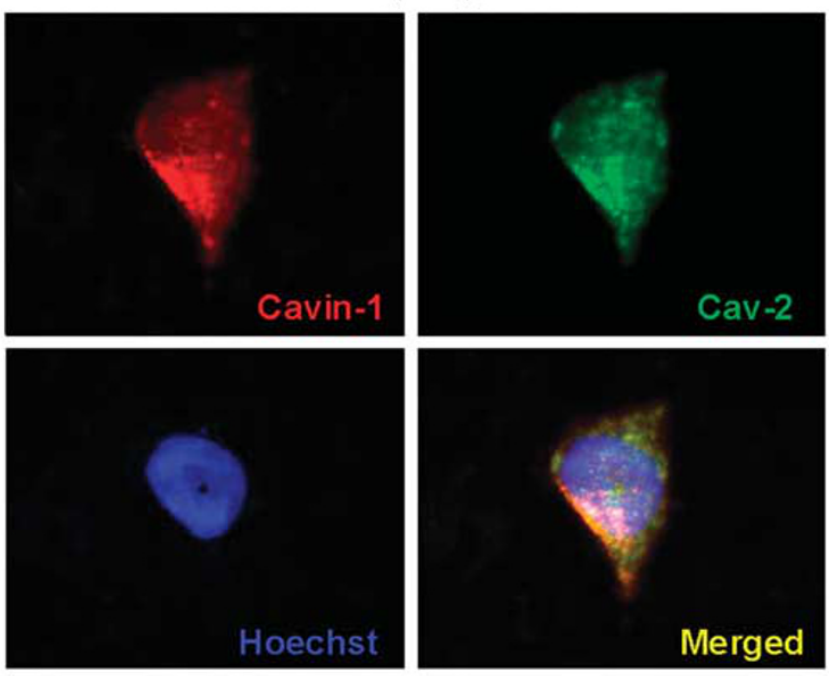

RD (63x)
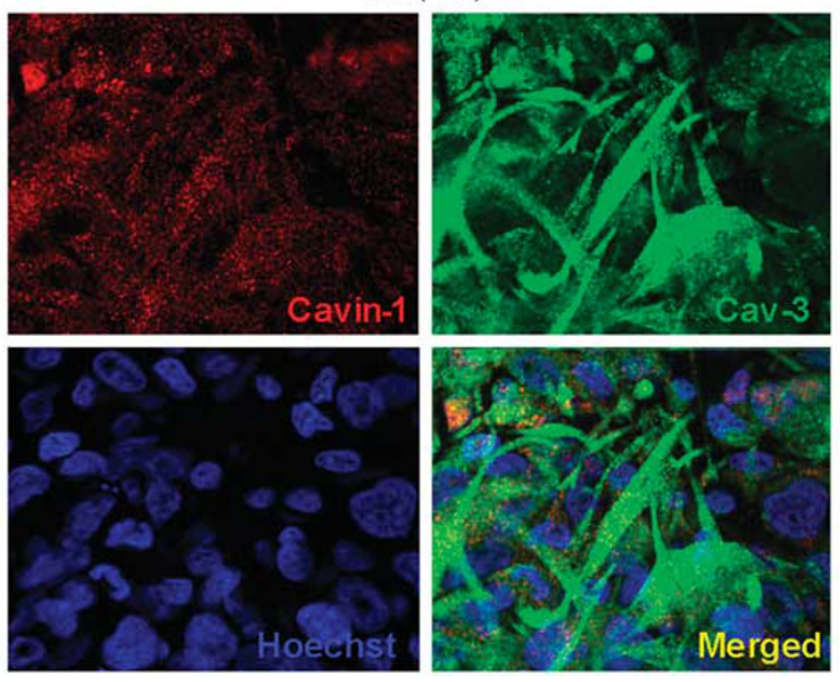

Figure 3 Continued.

\section{Immunofluorescence Analysis}

Cells were cultured onto $12 \mathrm{~mm}$ glass coverslips coated with FBS (Carlo Erba Reagents-Dasit Group, Cornaredo, Italy) and fixed with PFA for $15 \mathrm{~min}$ at room temperature. PFA was then quenched incubating the cells in $\mathrm{NH}_{4} \mathrm{Cl}(50 \mathrm{mM})$ for additional $15 \mathrm{~min}$. Cells were then washed with phosphate buffer solution (PBS)/sucrose (2\%) and treated with $0.1 \%$ Triton X-100 to allow cell permeabilization. Cells were then treated three times with $3 \%$ bovine serum albumin in PBS for $10 \mathrm{~min}$, and incubated for $3 \mathrm{~h}$ in a humidified atmosphere with the Cav-1 antibody (1:300 dilution), Cavin-1 antibody (1:200 dilution) alone or in the presence of the mouse Cav-1 antibody (1:100 dilution, purchased from Zymed-Life Technologies), Cav-2 antibody (1:100 dilution, purchased from $\mathrm{BD}$ ) or Cav-3 antibody (1:200 dilution, purchased from BD). After PBS washing, samples were incubated for $1 \mathrm{~h}$ with a diluted 1:500 anti-rabbit CY3-conjugated and/or anti-mouse Alexa 488 streptavidin-conjugated secondary antibody (Jackson ImmunoResearch Laboratories, West Grove, PA, USA). Hoechst staining (1:1000 in sterile water) was employed to visualize the cell nuclei. Cells were analyzed using a Zeiss Axiovert 200M epifluorescence microscope equipped with Apotome or a LSM510 Meta confocal microscope, using a Plan-Apochromat $\times 63 / 1.4$ NA oil objective (Carl Zeiss). Digital images were further examined using AxioVision 'Extended Focus Acquisition' module and AxioVision 'Inside4D' module software (Carl Zeiss).

\section{Cell Proliferation Assay}

Cells were seeded into 24-well plates (at a density of $15 \times 10^{3}$ cells). After 48 or $72 \mathrm{~h}$, cells were harvested, PFA-fixed and stained with Crystal violet (0.5\% in PBS with $20 \%$ methanol). 
a

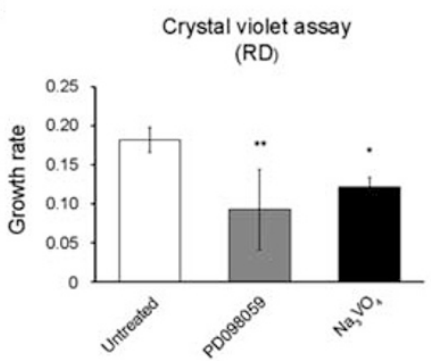

b
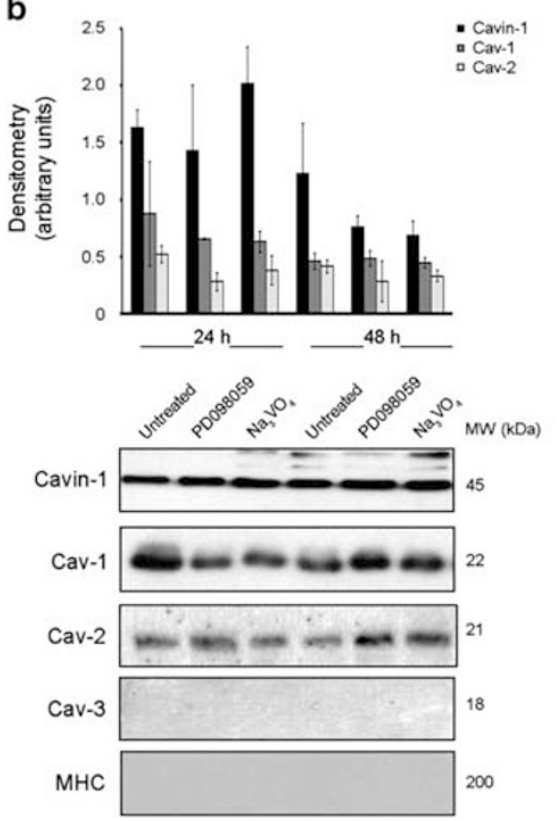

tubulin

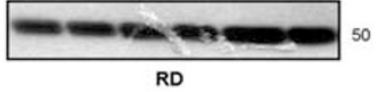

C

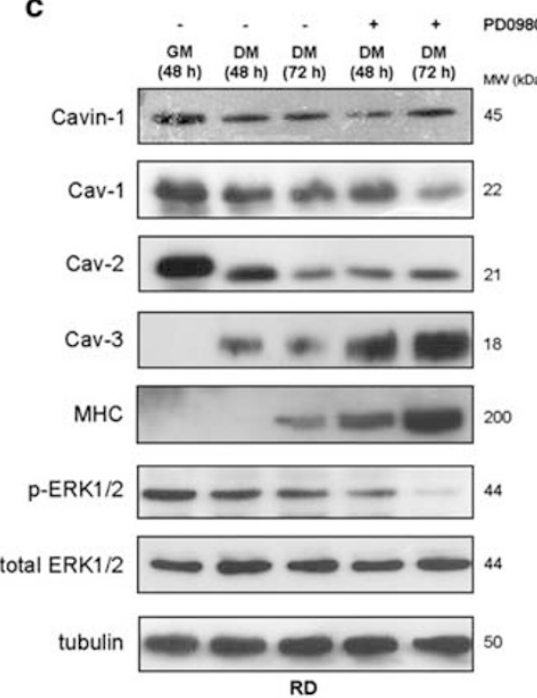

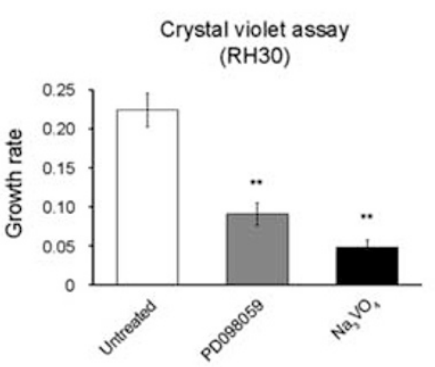
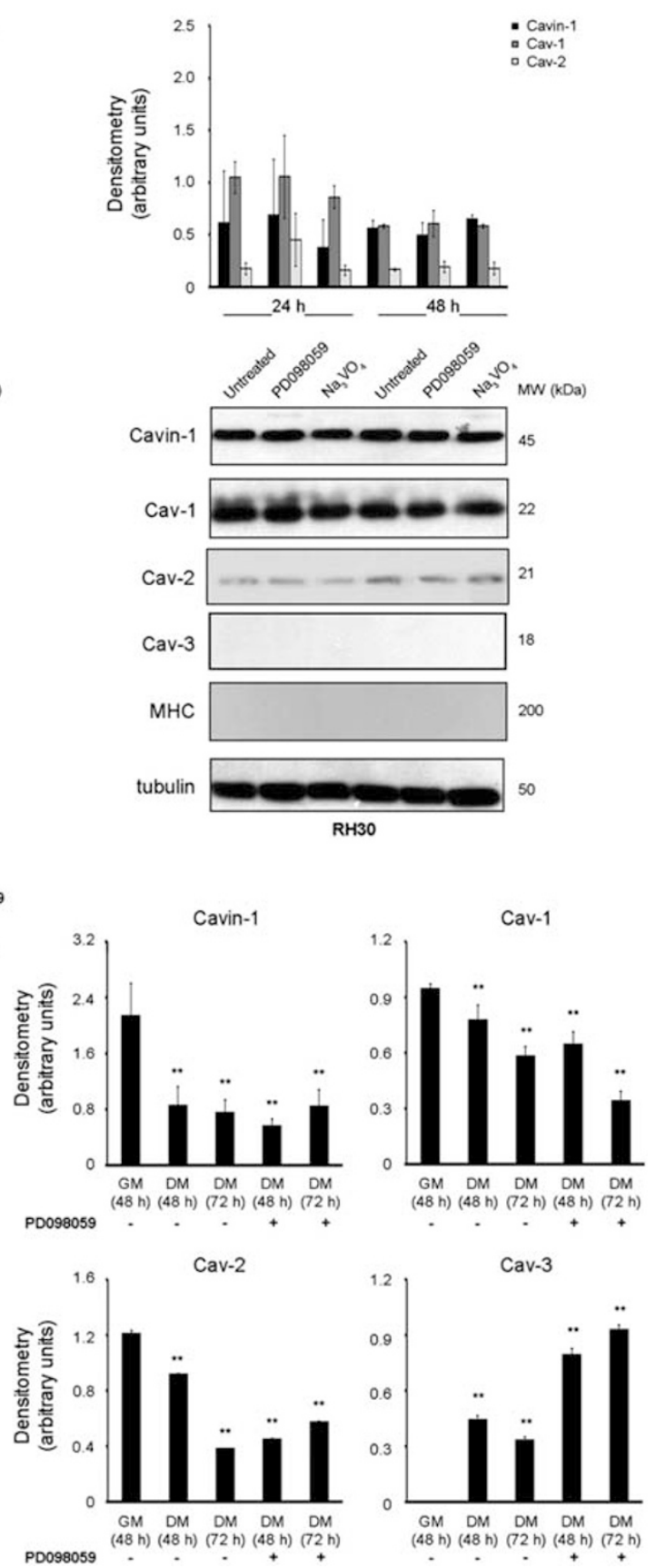
Absorbance was then measured by reading the plate at $570 \mathrm{~nm}$ emission wavelength. The growth rate was calculated using Microsoft Excel 2010 software. Images of cell proliferation assays reflect representative results of at least three independent experiments.

\section{Chemotaxis Assay}

Cells $\left(25 \times 10^{3}\right.$ in $50 \mu \mathrm{l}$ of DMEM with $5 \%$ FBS $)$ were seeded in the upper compartment of a Boyden chamber, containing gelatin-coated PVP-free polycarbonate filters ( $8 \mu \mathrm{m}$ pore size, Costar-Corning, Tewksbury, MA, USA) and DMEM with $10 \%$ FBS in the lower compartment. As a negative control, $1 \%$ FBS medium was used. After $5 \mathrm{~h}$ of incubation at $37^{\circ} \mathrm{C}$, cells migrated to the lower side of the filter were stained with Diff-Quik (Dade-Behring, GE Healthcare). Five random fields were counted for each triplicate sample.

\section{Cell Viability Assay}

The lysosomal accumulation of neutral red dye was used to evaluate the percentage of viable cells. ${ }^{63,64}$ Briefly, the cells were seeded into 96-well plates (at a density of $1.5 \times 10^{3}$ cells). After $24 \mathrm{~h}$, cells received doxorubicin $(0.15 \mathrm{ng} / \mathrm{ml})$ for $48 \mathrm{~h}$, before incubation for $2 \mathrm{~h}$ with neutral red dye $(40 \mu \mathrm{g} / \mathrm{ml})$ dissolved in DMEM with 5\% FBS. Cells were then washed with PBS and $100 \mu \mathrm{l}$ of elution medium (50\% ethanol and $1 \%$ acetic acid), followed by gentle shaking for $10 \mathrm{~min}$ so that complete dissolution was achieved. Absorbance was then measured by reading the plate at $540 \mathrm{~nm}$ emission wavelength. Results are presented as percentage of control values. Images of cell viability assays reflect representative results of at least three independent experiments.

\section{Soft Agar Colony Formation Assay}

Control RD cells and clones (overCav-1, shCav-1 and shCavin-1) were suspended in $1 \mathrm{ml}$ of medium containing $0.3 \%$ agar and applied onto $2 \mathrm{ml}$ of presolidified $0.6 \%$ agar plus $20 \%$ FBS in six-well plates $\left(10 \times 10^{5}\right.$ cells/well). After $1-2$ and 3 weeks of incubation, colonies were observed under a phase contrast microscope, photographed and counted. The results were expressed as the mean \pm s.d. of triplicate counts within the same experiment.

\section{Statistical Analysis}

The differences between the groups were analyzed by unpaired Student's $t$-tests and one-way ANOVA test (with
Dunnet's post test), using Prism 4 software for Windows (GraphPad Software). Statements of significance were based on a $P$-value of $<0.05$.

\section{Results}

\section{Cavin-1 is Expressed in Skeletal Muscle as well as in Myogenic RMS Tumors}

Immunofluorescence experiments were performed to analyze Cavin-1 distribution in mouse skeletal muscle. In cryosections from tibialis anterior muscle, Cavin-1 staining was expectedly found labeling endothelial cells in the blood vessels (BVs) (Figure 1a). In addition, Cavin-1 staining was localized in mononucleated cell elements surrounding the myofibers as well as at the plasmalemma of myofibers positive for MHC (Figure 1a). As the pool of mononucleated cells residing interposed among the myofibers may comprise several cell elements of different origin, including muscle SCs, fibroadipogenic progenitors and mesenchymal stem cells, ${ }^{65}$ we decided to address the question of whether Cavin-1 was specifically present in SCs. To this purpose, the protein levels of Cavin- 1 were analyzed in ex vitro experiments using SCs isolated from mouse skeletal muscle. Immunoblotting analysis carried out on membranous and soluble cell fractions showed the presence of Cavin-1 in proliferating SCs as well as its incremented expression during the myogenic differentiation, which was characterized by raised levels of Cav-3 (Figure 1b). Given the presence of Cavin-1 in skeletal muscle, we decided to evaluate whether Cavin-1 might be present in RMS, further evaluating the levels of Caveolins because of their close relationship. ${ }^{46}$ To this purpose, we employed an in silico approach taking advantage of microarray data that have been previously generated by the analysis of RMS tumors arisen in mouse models with specific genetic alterations. ${ }^{10}$ As shown by dot plot graphs (Figure 2a), the relative levels of Cavin-1 and Caveolins, as detected in ARMS $(n=14)$ and ERMS $(n=7)$ tumors, were similar to those found in skeletal muscle samples $(n=4)$ (Figure 2a). As represented by the Venn diagram, this in silico analysis allowed to identify 3136 and 2322 DEGs in ARMS and ERMS tumors with respect to skeletal muscle (fold-change $\geq 2$, corrected $P \leq 0.05$ ), respectively (Figure $2 \mathrm{~b}$ ). The analysis essentially indicated that Cavin-1, Cav-1 and Cav-2 were expressed in a similar manner in tumors and skeletal muscle, while only Cav-3 fell into the subset of DEGs that were significantly downregulated in ARMS compared with skeletal muscle (Figure 2b). We then

Figure 4 Expression analysis of Cavin-1 and Caveolins in RD and RH30 lines upon cell cycle arrest or myogenic differentiation induced by pharmacological treatments. (a) RD and RH30 cells were seeded into 24-well plates (at a density of $15 \times 10^{3}$ cells). After $24 \mathrm{~h}$, cells were treated with $10 \mu \mathrm{M}$ PD098059 (renewed every $24 \mathrm{~h}$ ) or $20 \mu \mathrm{M} \mathrm{Na} \mathrm{VO}_{4}$ (administered only once) for up to $48 \mathrm{~h}$. Cell proliferation was evaluated by Crystal violet assay. Histograms represent means \pm s.d. of growth rate index $(n=3)$. ${ }^{*} P<0.05 ;{ }^{*} P<0.001$. (b) Under the same conditions seen above, equal amounts of proteins derived from untreated and treated cells for 24 and $48 \mathrm{~h}$ were then western blotted for Cavin-1, Caveolins, MHC and tubulin ( $n=3$ ). Protein bands were quantified by densitometry after normalization with respect to tubulin $(n=3)$. (c) Subconfluent RD cells were mantained in DM over a 72-hlong time-course, in the absence or presence of daily administered $10 \mu \mathrm{M}$ PD098059. Cells were then harvested and protein homogenates western blotted for Cavin-1, Caveolins, MHC, ERK1/2 (phosphorylated and total forms) and tubulin. Protein bands were quantified by densitometry after normalization with respect to tubulin $(n=3)$. ${ }^{* *} P<0.001$. 
a
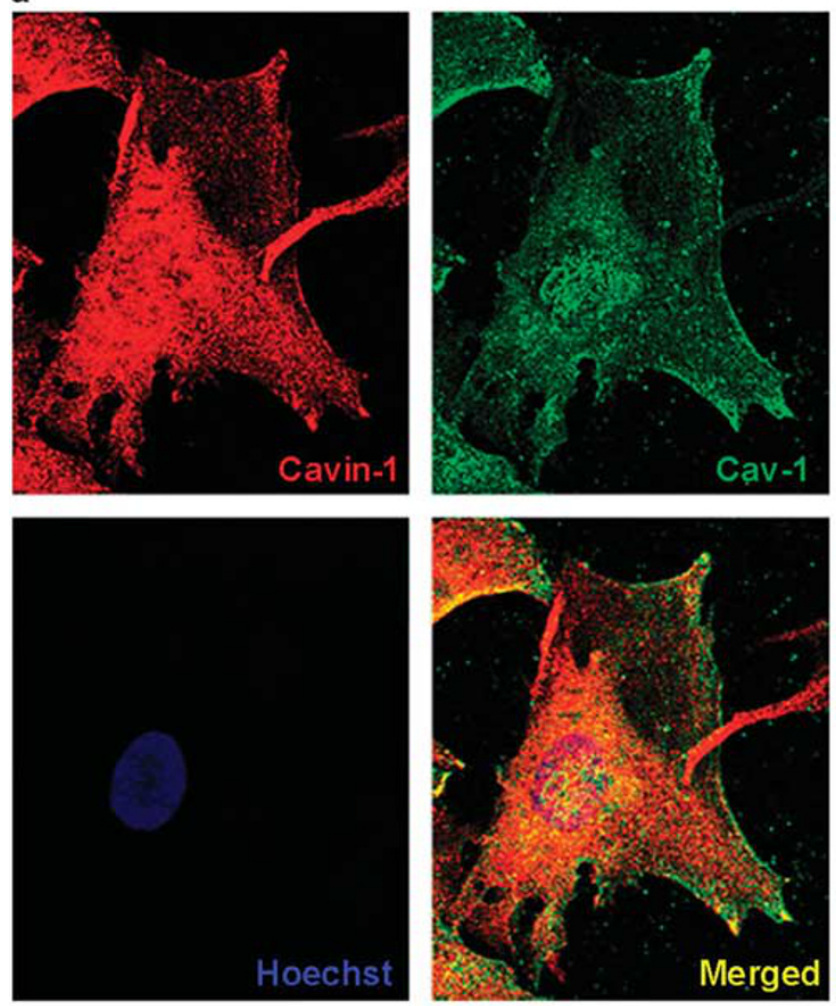

b

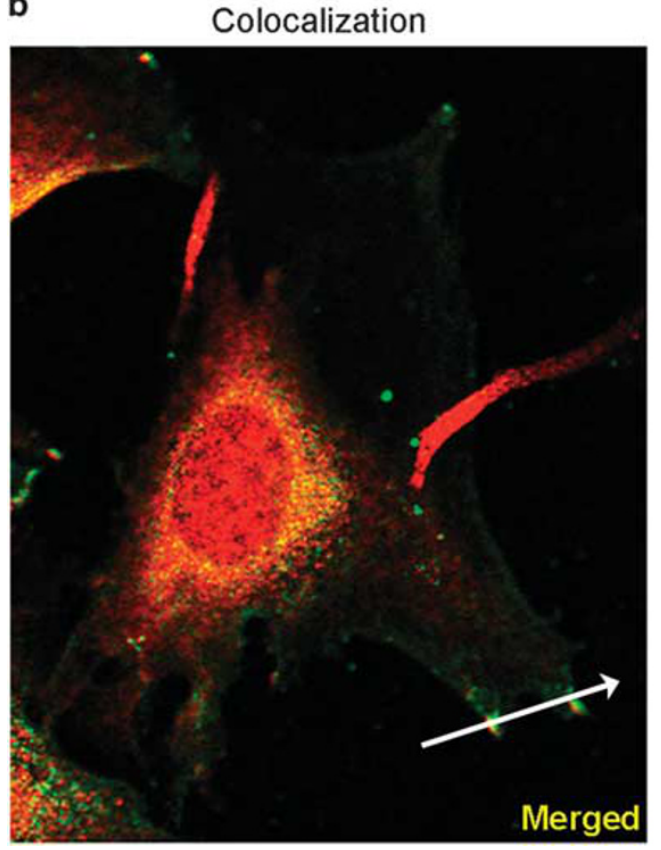

Intensity
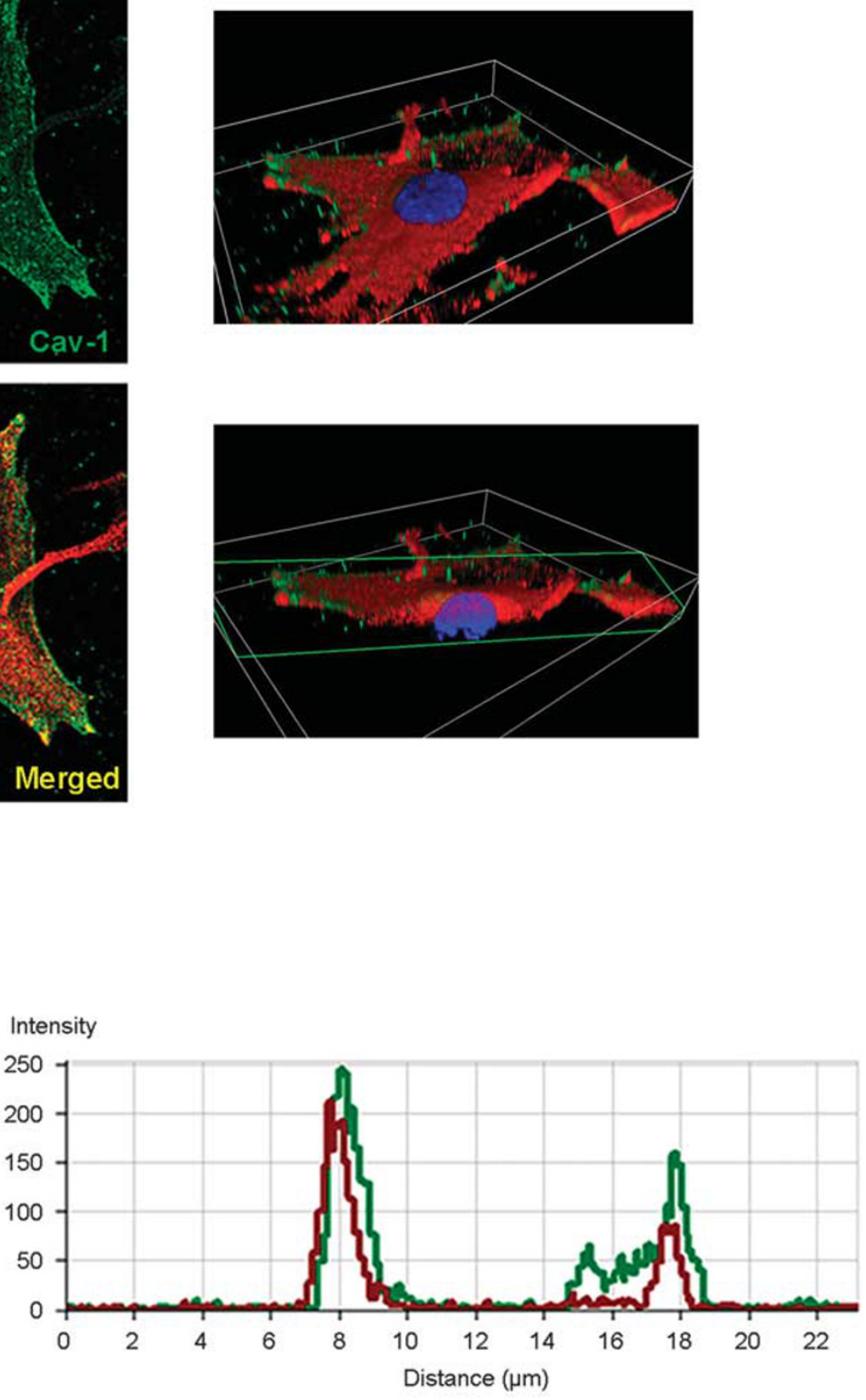

Intensity Ch2-T1 - Intensity Ch3-T2 -

Figure 5 Confocal microscopy analysis of Cavin-1 and Cav-1 subcellular localization. Confocal microscopy analysis was employed to analyze distribution of Cavin-1 and Cav-1 in RD cells. (a) Cavin-1 and Cav-1 localization was highlighted by means of the extended focus Z stack image (14 slides of $0.32 \mu \mathrm{m}$ ), combining each visual plane with the AxioVision software (left panels). Pictures were taken at $\times 63$ magnification. To outline the nuclear localization of Cavin-1, the clipped three-dimensional images (3D and YZ clip 3D images, respectively) were created, as depicted in the green rectangles (right panels), using the Inside4D function of AxioVision software 3D. (b) The cell surface colocalization of Cavin-1 and Cav-1 was outlined by using the colocalization module of AxioVision software. The graph shows the fluorescence intensity profiles of Cavin-1 (red curve) and Cav-1 (green curve) along the regions indicated by the white straight-line in the picture. (c) Either endogenous Cav-1 or Cavin-1 was immunoprecipitated in cell lysates (1 mg) derived from human and mouse cell lines cultured in GM or DM for $72 \mathrm{~h}$. Co-immunoprecipitated Cavin-1 or Cav-1 were then detected by immunoblotting. Pre-cleared samples and homogenates were loaded as negative and positive control, respectively. Results are representative of three independent experiments. 
C

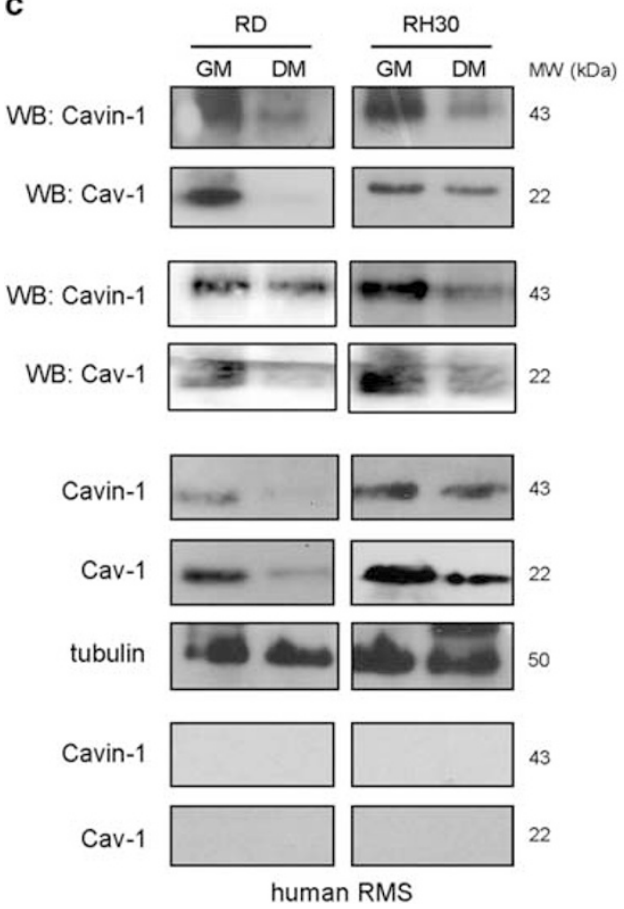

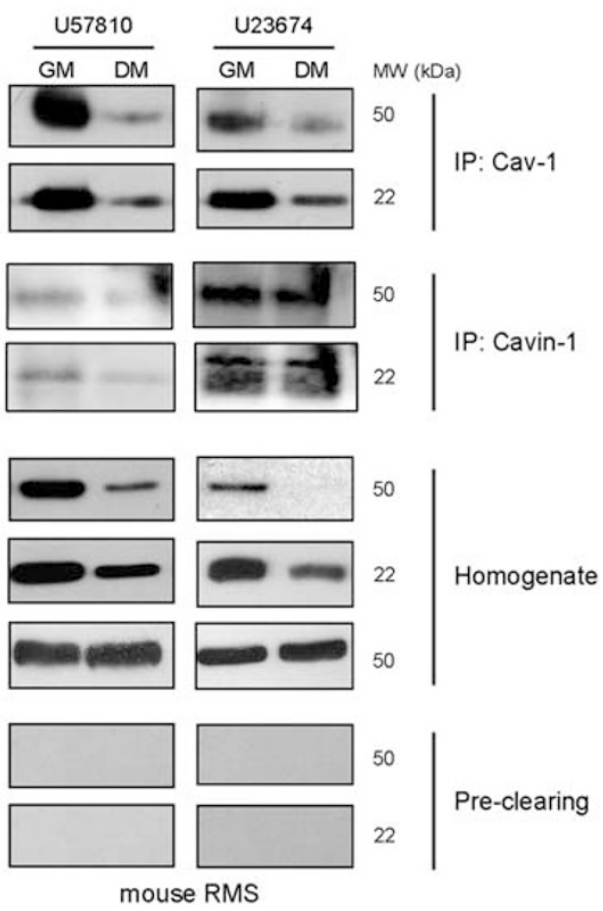

Figure 5 Continued.

analyzed the protein expression by immunoblotting using different RMS lines, including two primary tumor cultures established from RMS-bearing transgenic mice ${ }^{10}$ and four human RMS cell lines (see Materials and Methods for the genetic background characterizing each line). In mouse and human cells, the molecular weight of Cavin-1 protein band was $\sim 43$ and $50 \mathrm{kDa}$, respectively (Figure $3 \mathrm{a}$ ). In particular, Cavin-1 was always recognized in concomitance with Cav-1 and Cav-2 in cells cultured in GM, while stimulating a variable degree of myogenic differentiation by culturing the cells in DM for 3 days led to downregulation of Cavin-1, Cav1 and Cav-2 followed by upregulation of Cav-3 and MHC levels (Figure 3a). By immunofluorescence analysis we observed that Cavin-1 partially colocalized with either Cav-1 or Cav-2 during cell proliferation, as shown in RD cells (Figure 3b, upper panels). Conversely, Cavin-1 and Cav-3 did not colocalize, as observed during myodifferentiation of $\mathrm{RD}$ cells (Figure 3b, bottom panels). Analogous results were also observed in RH30 cells (not shown).

\section{Cavin-1, Cav-1 and Cav-2 Downregulation is Specifically} Related to Myogenic Differentiation of RMS Cells

To understand whether Cavin-1, Cav-1 and Cav-2 downregulation might be specifically related to the block of cell cycle rather than differentiation, we treated proliferating $\mathrm{RD}$ and RH30 cells with PD098059 or $\mathrm{Na}_{3} \mathrm{VO}_{4}$, which were reported to affect RMS cell proliferation via inhibition of the ERK signaling and phosphatase activity, respectively. ${ }^{66-68}$ As determined by Crystal violet assay, either treatment was effective in reducing cell proliferation in comparison to vehicle-treated cells (Figure 4a), but without affecting the protein levels of Cavin-1, Cav-1 and Cav-2, as shown by immunoblotting and relative densitometric analysis (Figure 4b). In these conditions, the inhibition of proliferation was not accompanied by concomitant differentiation, as the expression levels of Cav-3 and MHC were always undetectable (Figure 4b). Conversely, forcing the myogenic differentiation of $\mathrm{RD}$ cells by co-treatment with $\mathrm{DM}$ and PD098059 led to reduction in Cavin-1, Cav-1 and Cav-2 protein levels followed by increased levels of Cav-3 and MHC (Figure 4c).

These data suggest that concomitant presence of Cavin-1, Cav-1 and Cav-2 is mainly predictive of RMS cell growth, whereas downregulation of their protein levels seems to be a consequence of the differentiation program.

\section{Cavin-1 Interacts with Cav-1 at the Plasma Membrane of ERMS and ARMS Cells}

Confocal microscopy analysis was used to evaluate the subcellular localization of Cavin-1 and Cav-1 in RD cells. As shown in Figure 5a (left panels), Cavin-1 exhibited a broad cellular distribution, ranging from nuclei (highlighted via three-dimensional reconstruction images in the right panels) and cytosol to plasma membrane, whereas Cav-1 was more localized at the plasma membrane and to a lesser extent in the cytosol. Colocalization of Cavin-1 with Cav-1 was specifically detectable at the plasma membrane, as shown in merged images (yellow color) (Figure 5b). Moreover, Cav-1 and 


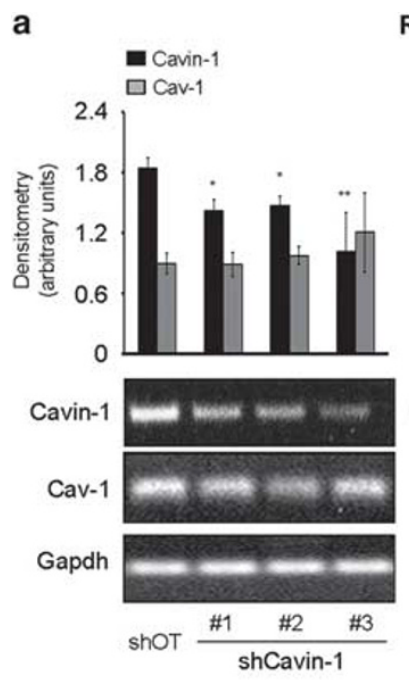

b

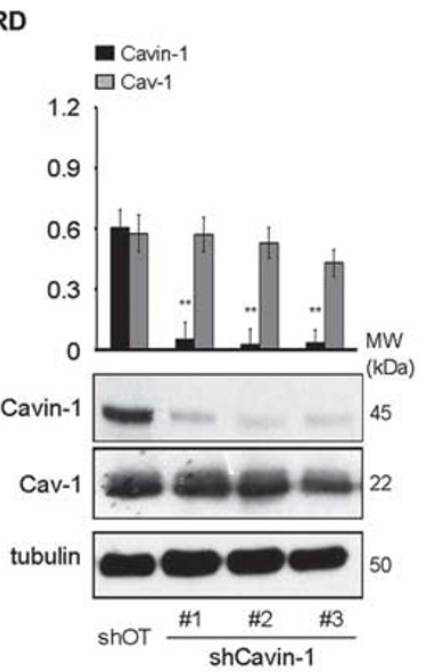

RD
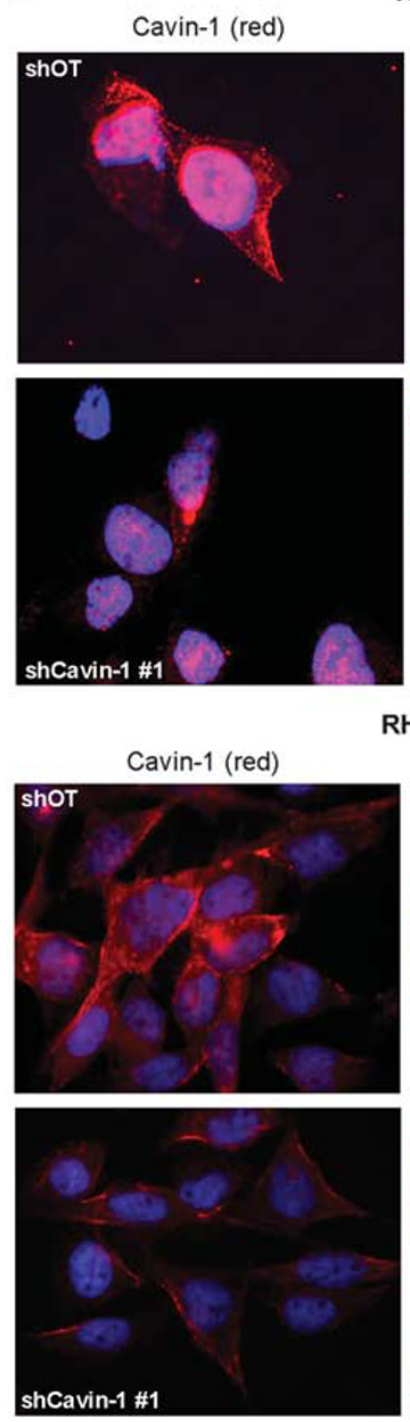

Cav-1 (green)
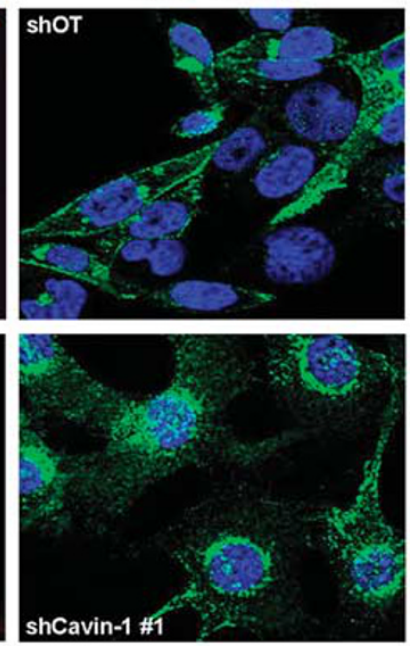

RH30
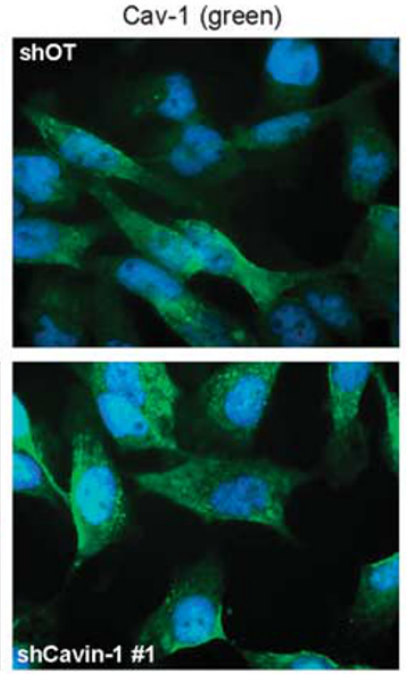

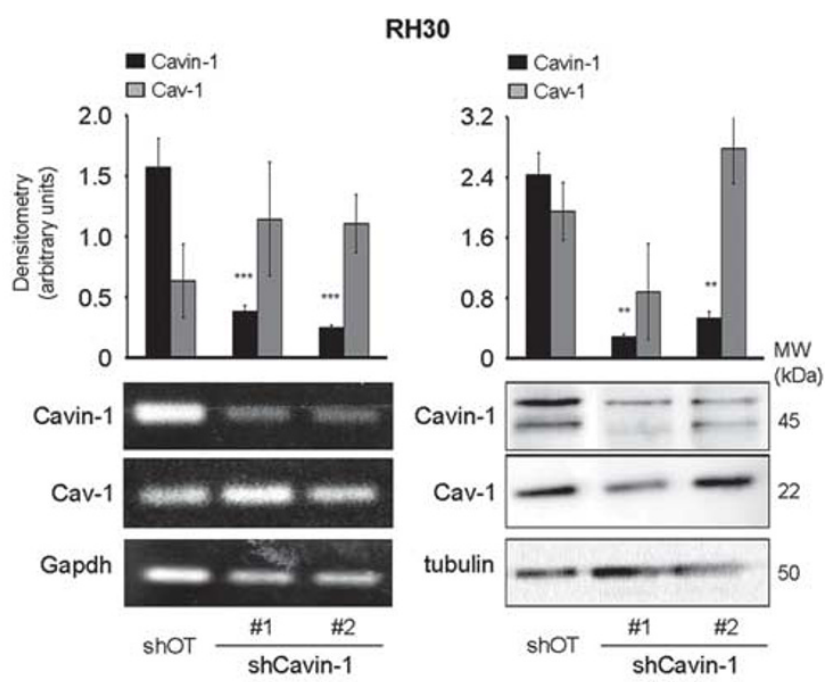

c

Crystal violet proliferation assay
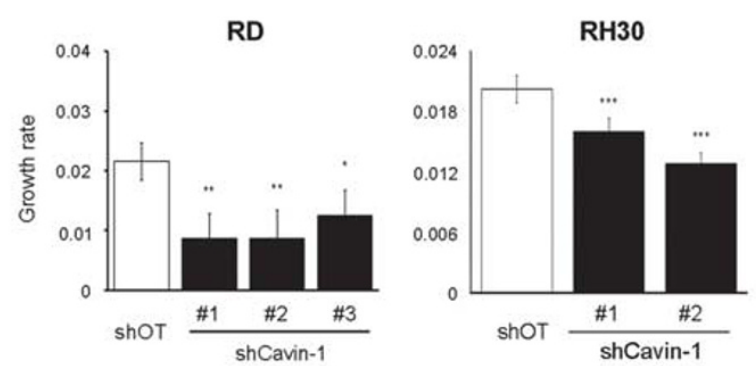

Boyden chamber migration assay
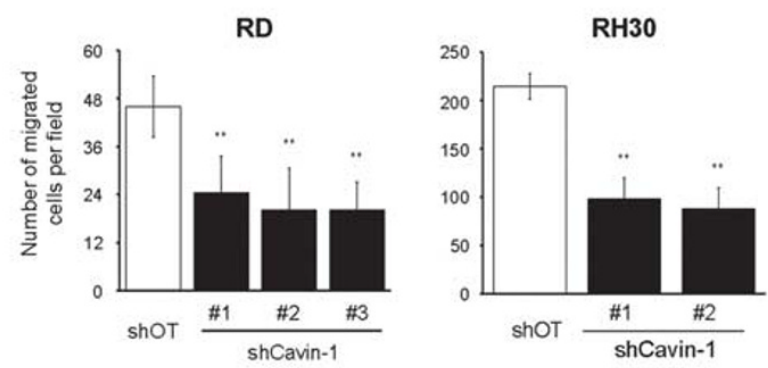

Neutral red viability assay
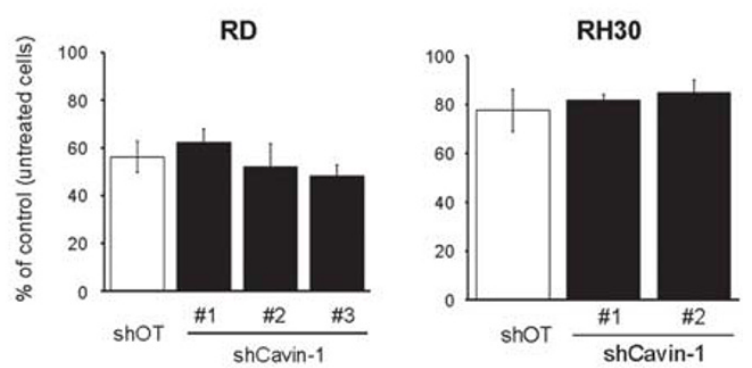
Cavin-1 partially colocalized also at the perinuclear regions presumably corresponding to Golgi apparatus, where both nascent proteins are synthesized. ${ }^{43}$

To address the question of whether Cavin- 1 and Cav-1 might specifically interact, we also carried out immunoprecipitation of endogenous Cav-1 or Cavin- 1 followed by immunoblotting against Cavin-1 and/or Cav-1 using the cell extracts obtained from four human and mouse RMS cell lines. These experiments clearly show that Cavin-1 and Cav-1 physically interact, especially during cell growth (Figure 5c).

Overall, these data suggest that Cavin-1 and Cav-1 form protein complexes at the plasma membrane of proliferating RMS cells.

\section{Cavin-1 Knockdown Decreases Cell Proliferation and Migration in the Embryonal RD and Alveolar RH30 Cell Lines}

To determine whether loss of Cavin-1 might affect the behavior of RMS cells, we knocked down Cavin-1 expression in human RD and RH30 cells. To this purpose, we selected different clones in which the transcript and protein levels of Cavin-1 were downregulated by stable delivery of shCavin-1 vectors in comparison to shOFF target (i.e., shOT) constructs, as shown by semiquantitative PCR and immunoblotting (Figure 6a). By immunofluorescence analysis, Cavin-1 labeling was consistently reduced at the plasma membrane and in the cytosol of shCavin-1 clones in comparison to shOT cells, with a residual signal remaining barely detectable in the nuclei of RD cells (Figure 6b).

As Cavin-1 depletion has been reported to trigger Cav-1 mislocalization followed by protein degradation, ${ }^{69}$ we evaluated the expression and localization of Cav-1 in shCavin-1 clones. In both RD and RH30 lines, there was no significant difference in Cav-1 transcript and protein levels between shCavin-1 and control shOT clones, as detected via semiquantitative PCR and immunoblotting (Figure 6a). Immunofluorescence analysis showed that the loss of Cavin1 triggered an intracellular accumulation of Cav- 1 in RD cells, which gave rise to a marked staining at the perinuclear regions (Figure 6b, upper panels). In addition, shCavin-1 clones in $\mathrm{RD}$ cells exhibited a residual nuclear staining (Figure 6b). Indeed, nuclear proteins are more resistant to knockdown mediated by shRNA because of the reduced availability of RNAi cellular machinery into the nucleus. ${ }^{70}$ In contrast, Cavin-1 downregulation in RH30 cells did not affect the subcellular localization of Cav-1 (Figure 6b, bottom panels). We next assayed the cell proliferation, migration and chemoresistance of the different clones by means of the Crystal violet, Boyden chamber and Neutral Red assays, respectively. We observed that shCavin- 1 clones exhibited a significant impairment of cell proliferation and migration in comparison to shOT cells, in both RD and RH30 lines (Figure 6c). Conversely, the loss of Cavin-1 did not affect the chemoresistance to doxorubicin in comparison to shOT cells (Figure 6c).

Collectively, these data indicate that Cavin-1 depletion significantly impairs the proliferation and migration, but not chemoresistance, of the embryonal $\mathrm{RD}$ and alveolar RH30 cells.

\section{The Modulation of Cav-1 Expression Impacts the Cavin-1 Levels and the Cancerous Behavior of the RD Cell Line}

We have recently demonstrated that Cav-1 overexpression favors RMS growth, migration and chemoresistance, whereas Cav-1 depletion inhibits cell growth and migration, further sensitizing RMS cells to cell apoptosis induced by chemotherapy drugs. ${ }^{54}$ Hence, we used specific $\mathrm{RD}$ clones in which Cav1 has been overexpressed or knocked down (overCav-1 and shCav-1 clones, respectively) to analyze the effects on Cavin-1 expression and cellular localization. Cav-1 overexpression or knockdown yielded increased or decreased protein levels of Cavin-1, respectively, as shown via immunoblotting (Figure 7a). Furthermore, immunoprecipitation experiments clearly showed that the amount of Cavin-1 and Cav-1 complexes was increased in Cav-1-overexpressing RD cells (Figure 7b). Immunofluorescence analysis showed that Cav-1 overexpression, yielding an increased Cav-1 staining at the plasma membrane as well as in intracellular perinuclear regions, resulted in an increased and diffused intracellular

Figure 6 Characterization of human RD and RH30 cells after Cavin-1 knockdown. After stable transfection with either shCavin-1 or shOT constructs, the antibiotic-resistant clones were subjected to evaluation of Cavin-1 and Cav-1 expression levels. To this purpose, cells seeded in 60 mm dishes (at a density of $12 \times 10^{4}$ cells) were maintained for $48 \mathrm{~h}$ in GM and then harvested. (a) Semi-quantitative PCR and immunoblotting analyses with relative densitometries showing the transcript and protein levels of Cavin-1 and Cav-1 in shOT and shCavin- 1 clones of RD (left panels) and RH30 (right panels) lines. Gapdh amplification was used to normalize the transcript levels. ${ }^{*} P<0.05 ;{ }^{* *} P<0.001 ;{ }^{* *} P<0.0001$. Protein bands were quantified by densitometry after normalization with respect to tubulin $(n=3)$. ${ }^{*} P<0.001$. (b) shCavin- 1 and shOT clones were seeded onto coverslips (at a density of $10 \times 10^{4}$ cells) and maintained in GM for $72 \mathrm{~h}$. Immunofluorescence analysis was then performed to visualize Cavin- 1 and Cav- 1 distribution in $\mathrm{RD}$ (upper panels) and RH30 (bottom panels) lines. Hoechst staining (blue) was employed to visualize the cell nuclei. Pictures were taken at $\times 63$ magnification. (c) Cell proliferation, migration and chemoresistance were evaluated in RD (left panels) and RH30 (right panels) lines after Cavin-1 knockdown. Cell proliferation was evaluated by Crystal violet assay. Histograms represent means \pm s.d. of growth rate index $(n=4)$. ${ }^{*} P<0.05 ;{ }^{*} P<0.001$; ${ }^{* *} P<0.0001$. Cell migration was evaluated using a modified Boyden chamber assay. The migration index was calculated through the ratio between the mean number of migrated shCavin-1 clones with respect to controls, as counted in five randomly chosen fields ( $n=3$ ). ${ }^{* *} P<0.001$. Chemoresistance was evaluated by means of neutral red assay in the absence or presence of $0.15 \mathrm{ng} / \mathrm{ml}$ doxorubicin for $24 \mathrm{~h}$. Histograms represent means \pm s.d. of viable cells with respect to vehicle-treated cells $(n=4)$. 

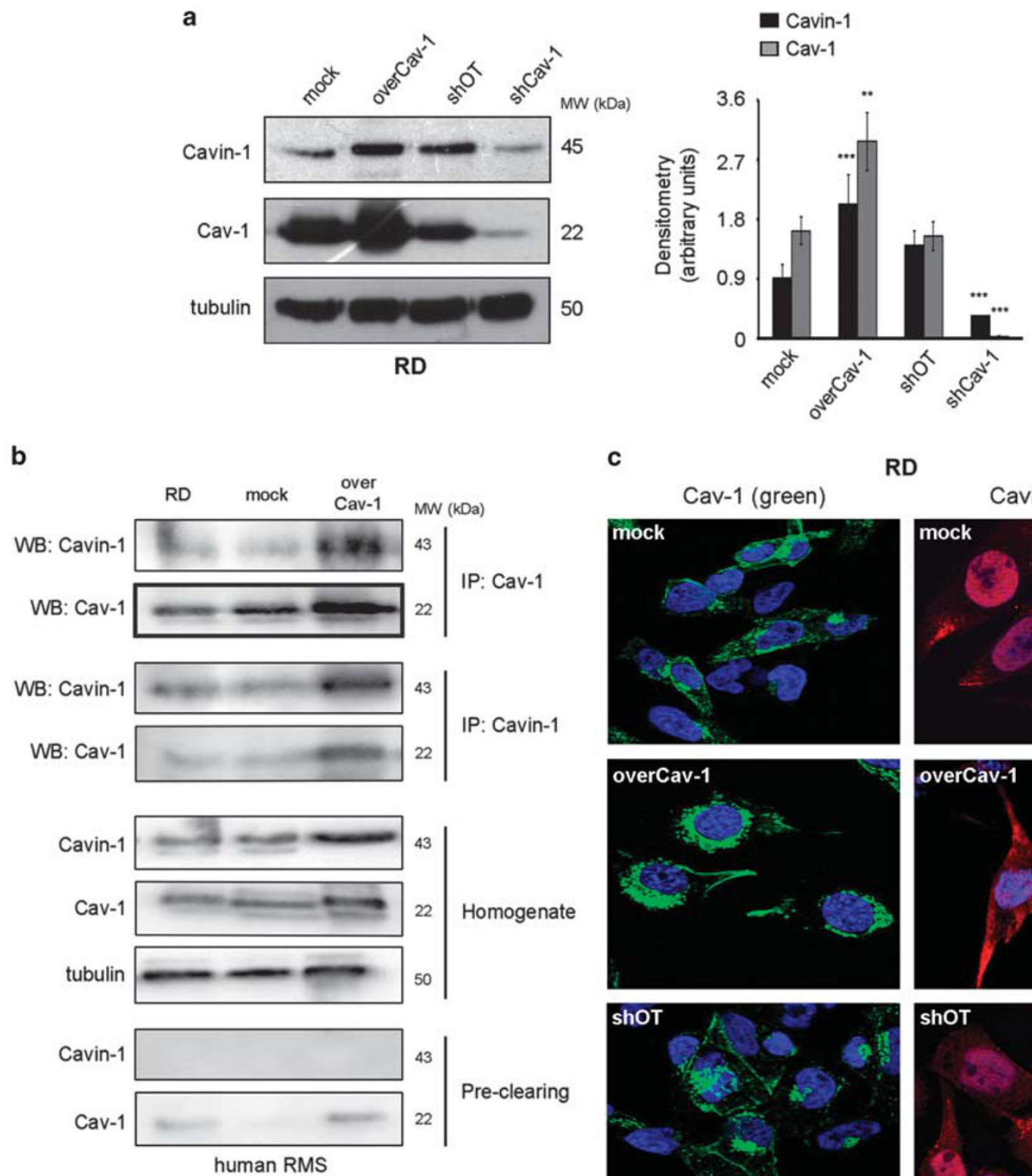

C
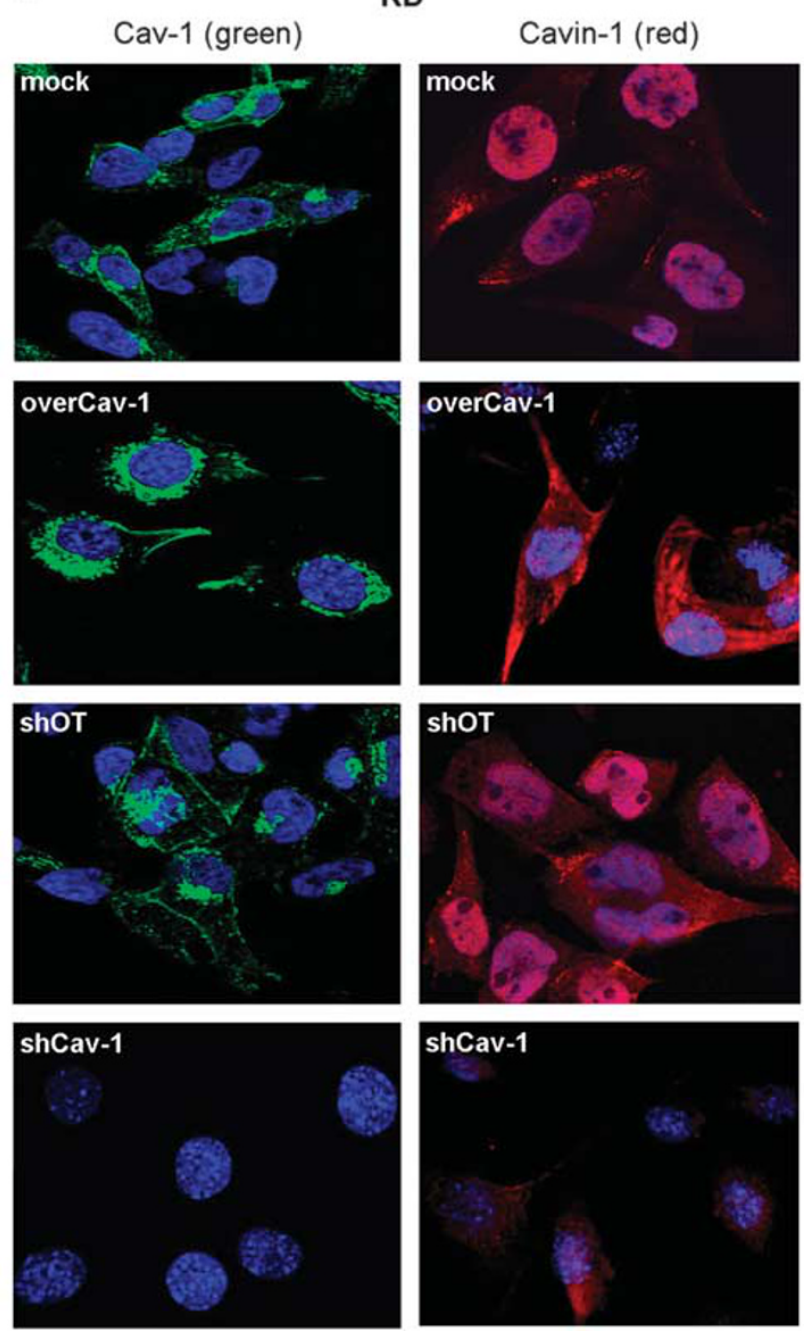

Figure 7 Evaluation of levels and subcellular distribution of Cavin-1 after Cav-1 overexpression or knockdown. Human RD cells were stably transfected with either Cav-1 construct (overCav-1) or shCav-1 construct plus relative mock and shOT vectors, respectively. (a) Cells seeded in $60 \mathrm{~mm}$ dishes (at a density of $12 \times 10^{4}$ cells) were maintained for $48 \mathrm{~h}$ in GM and then harvested. The relative protein homogenates were immunoblotted for Cavin-1, Cav-1 and tubulin. Protein bands were quantified by densitometry after normalization with respect to tubulin $(n=3)$. ${ }^{* *} P<0.001$; ${ }^{* * *} P<0.0001$. (b) Endogenous Cav-1 or Cavin-1 was immunoprecipitated in cell lysates $(1 \mathrm{mg})$ of the different clones cultured in GM for 72 h. Co-immunoprecipitated Cavin-1 or Cav- 1 was then detected by immunoblotting. Pre-cleared samples and homogenates were loaded as negative and positive control, respectively. Results are representative of three independent experiments. (c) OverCav-1 and shCav-1 clones plus relative controls were seeded onto coverslips (at a density of $10 \times 10^{4}$ ) and maintained in GM for $72 \mathrm{~h}$. Immunofluorescence analysis was then performed to visualize Cav-1 (green) and Cavin-1 (red) distribution. Hoechst staining (blue) was employed to visualize the cell nuclei. Pictures were taken at $\times 63$ magnification. 
a
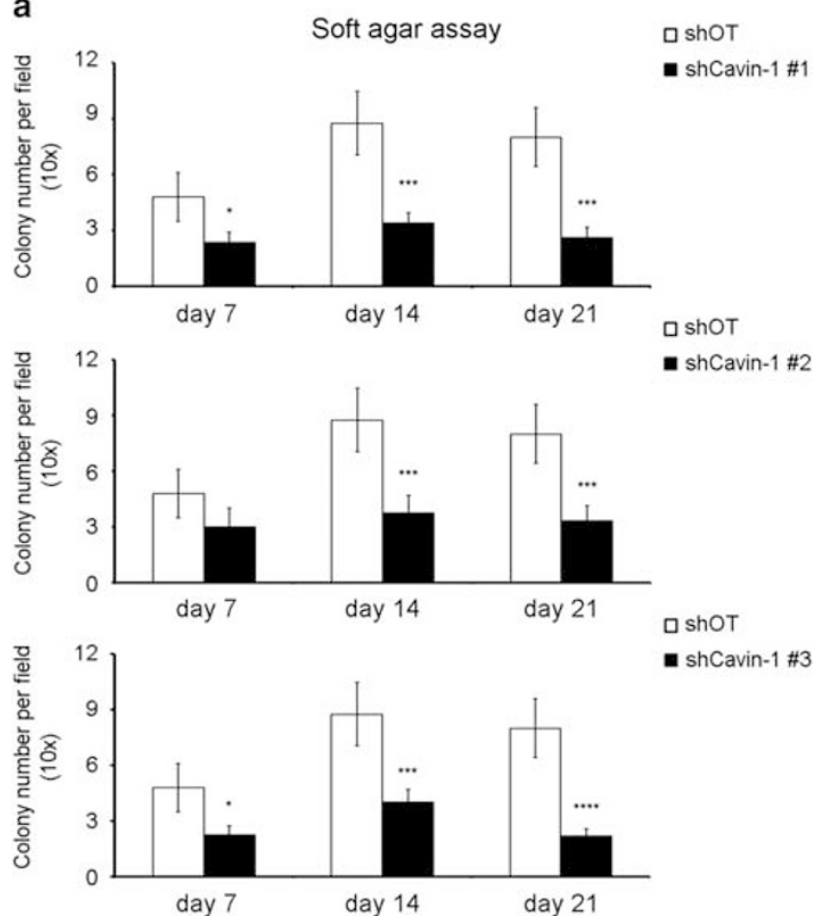

b

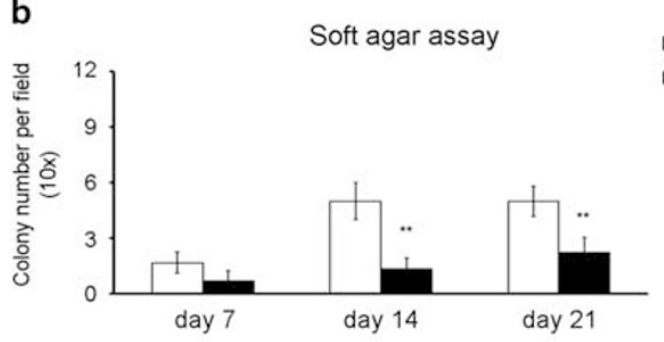

C

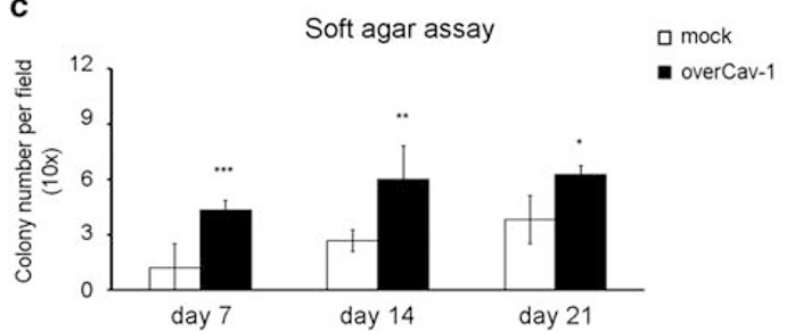

Figure 8 Analysis of the anchorage-independent cell growth in engineered RD cells. A soft agar assay was performed to evaluate the ability of RD cells to grow in a substrate-independent manner after knockdown of Cavin-1 (a) or Cav-1 (b) and overexpression of Cav-1 (c). Values obtained by quantification of the colony numbers are the means \pm s.d. of at least three independent experiments. ${ }^{*} P<0.05$; ${ }^{* *} P<0.01 ;{ }^{* * *} P<0.001 ; * * * * P<0.0001$.

Cavin-1 staining (Figure 7c). Conversely, Cav-1 depletion led to almost complete loss of Cavin-1 staining (Figure 7c).

Taken together, these data suggest that the levels of Cav-1 seem to influence those of Cavin-1 and not vice versa, at least in $\mathrm{RD}$ cells.

\section{Cavin-1 and Cav-1 are Both Required to Confer} Anchorage-Independent Cell Growth in the RD Line

Normal cells require a solid substratum to proliferate, whereas malignant cells gain the ability to grow regardless of their attachment status. In this regard, the cell anchorageindependent growth represents an important hallmark predictive of cellular transformation.

To address the question of whether Cavin- 1 and Cav- 1 may contribute to anchorage-independent cell growth, we performed a soft agar colony formation assay using $\mathrm{RD}$ cells. Either loss of Cavin-1 or Cav-1 was detrimental to anchorageindependent cell growth, as shCavin-1 clones formed fewer colonies (Figure 8a), whereas shCav-1 clones had completely lost the ability to form colonies in comparison to control shOT cells (Figure 8b). Conversely, Cav-1-overexpressing cells more quickly formed highly dense colonies in comparison to mock cells (Figure 8c).

These data indicate that loss of either Cavin-1 or Cav-1 impairs the ability of $\mathrm{RD}$ cells to grow in an anchorageindependent manner, whereas the gain of Cav-1 and the concomitant increase of Cavin-1 correlated with an incremented anchorage-independent cell growth.

\section{DISCUSSION}

Cavin-1, also known as polymerase transcription released factor, is a soluble protein that was originally identified as a nuclear factor cooperating with RNA polymerase I during the transcription process $s^{71,72}$ as well as interacting with the BFCOL1 (binding factor of a type-I collagen promoter) zincfinger transcription factor. ${ }^{73}$ Since then, Cavin-1 was also identified in lipid rafts, ${ }^{74}$ especially in adipocytes, ${ }^{75-78}$ where it has an active role during hormone-sensitive lipolysis. ${ }^{77,78}$

Over the past years some works have unveiled that this versatile protein even specifically cooperates with Cav-1 in the morphogenesis of caveolae, ${ }^{74-78}$ specialized microdomains of the plasma membrane that in several cell types represent the primary sites of important processes such as the endocytosis and signal transduction. ${ }^{37}$ In particular, Cavin-1 seems to have a pivotal role as protein cargo facilitating the transport of Cav-1 oligomers from the Golgi compartments toward the plasma membrane, whereby their insertion into the inner membranous leaflet actively participates in the establishment of caveolar domains by triggering the membrane curvature. Consistent with this, loss of either Cavin-1 or Cav-1 in mouse models triggers the flattening of caveolar domains and reflects in partially overlapping phenotypes characterized by the onset of different diseases. For example, deficiency of Cavin-1 in skeletal muscle has been associated with human lipodystrophy, muscular dystrophy and cardiac dysfunction. ${ }^{79-84}$ In accordance, mice lacking Cavin-1 exhibit a lipodystrophic phenotype $^{48}$ as well as an altered metabolic flux among multiple tissues, which suggests a role of Cavin-1 in the coordination of peripheral glucose and fatty-acid storage and utilization..$^{85}$ 
Cavin-1 has been also reported to have a pivotal role for the initiation of membrane repair upon injury in skeletal muscle. ${ }^{86}$ In mouse skeletal muscle we recognized Cavin-1 localizing in the mononucleated cell elements (i.e., SCs) surrounding the myofibers as well as at the plasmalemma of differentiated myofibers. During the ex vitro experiments ideally resembling the process of muscle regeneration occurring in vivo, when upon injury SCs escape quiescence and proliferate toward the damaged site to differentiate into newly formed myofibers, we observed increased protein levels of Cavin-1 in both the cytosolic and membranous fractions of SCs committed toward differentiation, therefore suggesting that Cavin-1 could be especially required for skeletal muscle formation during embryogenesis and muscle repair in the adult life.

Skeletal muscle also represents one of the major source of cell precursors that, in the presence of genetic lesions, may undertake a tumorigenic route resulting in the development of RMS, the most frequent soft tissue tumor of childhood. ${ }^{1-3}$ In this context, we found Cavin-1 expression to be always matching with Cav-1 and Cav-2 in proliferating human lines and mouse primary cultures established from tumors occurring in transgenic mice that faithfully recapitulate the appearance and progress of RMS. ${ }^{10,13}$ We detected a slight difference in the molecular weight of human and mouse Cavin-1 forms (i.e., 43.5 vs $50 \mathrm{kDa}$, respectively), suggesting the potential occurrence of posttranslational modifications. In this regard, one N-terminal acetylation site and four phosphorylation sites localized to Ser-36, Ser-40, Ser-365 and Ser-366 have been mapped along Cavin- 1 sequence. ${ }^{76}$ Cavin1 exhibited a broad subcellular localization in both human and mouse RMS cultures, ranging from nuclei and cytosol to plasma membrane. Unlike the muscle cells, the defective differentiation program observed in cancerous RMS cell elements $^{2}$ was characterized by downregulation of Cavin-1, Cav-1 and Cav-2 expression.

In different types of cancer, including breast cancer, ${ }^{87}$ lung cancer $^{88}$ and prostate cancer, ${ }^{89}$ the role of Cavin-1 is gradually assuming significant proportions and recent lines of evidence have put forward its dual behavior. For example, Cavin-1 was reported to decrease the malignant behavior of prostate PC3 cancer cells through different mechanisms, ${ }^{89-93}$ although being essential for the tumor-promoting effect of Cav-1 in pancreatic cancer ${ }^{94}$ and for multidrug resistance in breast cancer lines. ${ }^{95}$ By analogy, even the role of Cav-1 in cancer appears to be ambiguous, because Cav-1 may behave as either a tumor suppressor or oncopromoter depending on the type of tumor. ${ }^{96-101}$

Our data argue for an important role of Cavin-1 as essential partner of Cav-1 in RMS progression, as we clearly observed that loss of either Cavin-1 or Cav-1 was sufficient to impair cell proliferation, migration and anchorage-independent cell growth, a characteristic predictive of cell transformation in vitro and in vivo. Consistent with this, we also found that an incremental expression of Cavin-1 in RD cells, as causally obtained upon Cav-1 overexpression, led to a very aggressive cell behavior, which was characterized by a remarkable anchorage-independent cell growth. Hence, the plasma membrane interaction of Cavin-1 and Cav-1 may represent an important initiation signal for specific downstream pathways underlying the proliferation, migration and survival of RMS cells. In this context, the formation of Cavin-1 and Cav-1 complexes has been shown to promote a p53dependent premature senescence in fibroblasts exposed to oxidative stress ${ }^{102,103}$ and to regulate the internalization of IGF1R in human Hacat cells. ${ }^{104,105}$ Hence, it will be important to assess whether Cavin-1 and Cav-1 complexes may influence specific targets, such as p53 and IGF1R, that play a central role in RMS progression. ${ }^{17,106}$

It is also of interest that we found Cavin- 1 colocalizing with Cav-2 in proliferating RMS cells. Although we primarily focused on the interaction between Cavin-1 and Cav-1, a potential involvement of Cavin-1 and Cav-2 complexes in RMS cell survival and cancerous behavior cannot be ruled out.

Overall, the data of this work indicate Cavin- 1 and Cav- 1 as potential molecular targets for counteracting the proliferation, migration and clonogenic potential of RMS cells.

\section{ACKNOWLEDGMENTS}

This work was supported by the Fondazione Cariplo grant to E.M., Grant NEDD - Network Enabled Drug Design, Regione Lombardia to E.M. and University of Brescia research fund (ex 60\%) to A.F., E.M. and S.M.

\section{DISCLOSURE/CONFLICT OF INTEREST}

The authors declare no conflict of interest.

1. Parham DM, Alaggio R, Coffin CM. Myogenic tumors in children and adolescents. Pediatr Dev Pathol 2012;15:211-238.

2. Keller C, Guttridge DC. Mechanisms of impaired differentiation in rhabdomyosarcoma. FEBS J 2013;280:4323-4334.

3. Zanola A, Rossi S, Faggi F et al. Rhabdomyosarcomas: an overview on the experimental animal models. J Cell Mol Med 2012;16:1377-1391.

4. Tiffin N, Williams RD, Shipley J et al. PAX7 expression in embryonal rhabdomyosarcoma suggests an origin in muscle satellite cells. $\mathrm{Br}$ J Cancer 2003;89:327-332.

5. Morotti RA, Nicol KK, Parham DM et al. An immunohistochemical algorithm to facilitate diagnosis and subtyping of rhabdomyosarcoma: the children's oncology group experience. Am J Surg Pathol 2006;30:962-968.

6. Ren YX, Finckenstein FG, Abdueva DA et al. Mouse mesenchymal stem cells expressing PAX-FKHR form alveolar rhabdomyosarcomas by cooperating with secondary mutations. Cancer Res 2008;68: 6587-6597.

7. Charytonowicz E, Cordon-Cardo C, Matushansky I et al. Alveolar rhabdomyosarcoma: is the cell of origin a mesenchymal stem cell? Cancer Lett 2009;279:126-136.

8. Hettmer S, Liu J, Miller CM et al. Sarcomas induced in discrete subsets of prospectively isolated skeletal muscle cells. Proc Natl Acad Sci USA 2011;108:20002-20007.

9. Linardic CM, Downie DL, Qualman S et al. Genetic modeling of human rhabdomyosarcoma. Cancer Res 2005;65:4490-4495.

10. Rubin BP, Nishijo K, Chen $\mathrm{HI}$ et al. Evidence for an unanticipated relationship between undifferentiated pleomorphic sarcoma and embryonal rhabdomyosarcoma. Cancer Cell 2011;19:177-191.

11. Langenau DM, Keefe MD, Storer NY et al. Effects of RAS on the genesis of embryonal rhabdomyosarcoma. Genes Dev 2007;21: 1382-1395.

12. Keller C, Capecchi MR. New genetic tactics to model alveolar rhabdomyosarcoma in the mouse. Cancer Res 2005;65:7530-7532. 
13. Keller C, Arenkiel BR, Coffin CM et al. Alveolar rhabdomyosarcomas in conditional Pax3:Fkhr mice: cooperativity of Ink4a/ARF and Trp53 loss of function. Genes Dev 2004;18:2614-2626.

14. Abraham J, Nuñez-Álvarez $Y$, Hettmer $S$ et al. Lineage of origin in rhabdomyosarcoma informs pharmacological response. Genes Dev 2014;28:1578-1591.

15. Hatley ME, Tang W, Garcia MR et al. A mouse model of rhabdomyosarcoma originating from the adipocyte lineage. Cancer Cell 2012;22:536-546.

16. Wolden SL, Alektiar KM. Sarcomas across the age spectrum. Semin Radiat Oncol 2010;20:45-51.

17. Abraham J, Prajapati SI, Nishijo K et al. Evasion mechanisms to Igf1 $\mathrm{r}$ inhibition in rhabdomyosarcoma. Mol Cancer Ther 2011;10:697-707.

18. Ayalon D, Glaser T, Werner $\mathrm{H}$. Transcriptional regulation of IGFreceptor gene expression by the PAX3-FKHR oncoprotein. Growth Horm IGF Res 2001;11:289-297.

19. Rikhof B, de Jong S, Suurmeijer AJ et al. The insulin-like growth factor system and sarcomas. J Pathol 2009;217:469-482.

20. Taylor JG, Cheuk AT, Tsang PS et al. Identification of FGFR4-activating mutations in human rhabdomyosarcomas that promote metastasis in xenotransplanted models. J Clin Invest 2009;119:3395-3407.

21. Shern JF, Chen L, Chmielecki J et al. Comprehensive genomic analysis of rhabdomyosarcoma reveals a landscape of alterations affecting a common genetic axis in fusion-positive and fusion-negative tumors. Cancer Discov 2014;4:216-231.

22. Lee $\mathrm{Y}$, Kawagoe R, Sasai $\mathrm{K}$ et al. Loss of suppressor-of-fused function promotes tumorigenesis. Oncogene 2007;26:6442-6447.

23. Donehower LA, Harvey M, Slagle BL et al. Mice deficient for p53 are developmentally normal but susceptible to spontaneous tumours. Nature 1992;356:215-221.

24. Kohashi $\mathrm{K}$, Oda $\mathrm{Y}$, Yamamoto $\mathrm{H}$ et al. Alterations of RB1 gene in embryonal and alveolar rhabdomyosarcoma: special reference to utility of pRB immunoreactivity in differential diagnosis of rhabdomyosarcoma subtype. J Cancer Res Clin Oncol 2008;134: 1097-1103.

25. Chamberlain JS, Metzger J, Reyes $M$ et al. Dystrophin-deficient mdx mice display a reduced life span and are susceptible to spontaneous rhabdomyosarcoma. FASEB J 2007;21:2195-2204.

26. Fernandez $K$, Serinagaoglu $Y$, Hammond $S$ et al. Mice lacking dystrophin or alpha sarcoglycan spontaneously develop embryonal rhabdomyosarcoma with cancer-associated p53 mutations and alternatively spliced or mutant Mdm2 transcripts. Am J Pathol 2010;176:416-434.

27. Hosur V, Kavirayani A, Riefler J et al. Dystrophin and dysferlin double mutant mice: a novel model for rhabdomyosarcoma. Cancer Genet 2012:205:232-241.

28. Wang Y, Marino-Enriquez A, Bennett RR et al. Dystrophin is a tumor suppressor in human cancers with myogenic programs. Nat Genet 2014;46:601-606.

29. Schmidt WM, Uddin $M H$, Dysek $S$ et al. DNA damage, somatic aneuploidy, and malignant sarcoma susceptibility in muscular dystrophies. PLoS Genet 2011;7:e1002042.

30. Fanzani A, Monti E, Donato R et al. Muscular dystrophies share pathogenetic mechanisms with muscle sarcomas. Trends Mol Med 2013;19:546-554.

31. Galili N, Davis RJ, Fredericks WJ et al. Fusion of a fork head domain gene to PAX3 in the solid tumour alveolar rhabdomyosarcoma. Nat Genet 1993;5:230-235.

32. Barr FG, Galili N, Holick J et al. Rearrangement of the PAX3 paired box gene in the paediatric solid tumour alveolar rhabdomyosarcoma. Nat Genet 1993:3:113-117.

33. Davis RJ, D'Cruz CM, Lovell MA et al. Fusion of PAX7 to FKHR by the variant $\mathrm{t}(1 ; 13)(\mathrm{p} 36 ; \mathrm{q} 14)$ translocation in alveolar rhabdomyosarcoma. Cancer Res 1994;54:2869-2872.

34. Graf Finckenstein F, Shahbazian V, Davicioni E et al. PAX-FKHR function as pangenes by simultaneously inducing and inhibiting myogenesis. Oncogene 2008;27:2004-2014.

35. Keller C, Hansen MS, Coffin CM et al. Pax3:Fkhr interferes with embryonic Pax3 and Pax7 function: implications for alveolar rhabdomyosarcoma cell of origin. Genes Dev 2004;18:2608-2613.

36. Kikuchi K, Hettmer S, Aslam Ml et al. Cell-cycle dependent expression of a translocation-mediated fusion oncogene mediates checkpoint adaptation in rhabdomyosarcoma. PLoS Genet 2014;10:e1004107.
37. Parton RG, del Pozo MA. Caveolae as plasma membrane sensors, protectors and organizers. Nat Rev Mol Cell Biol 2013;14:98-112.

38. Williams TM, Lisanti MP. The caveolin proteins. Genome Biol 2004;5: 214.

39. Razani B, Woodman SE, Lisanti MP. Caveolae: from cell biology to animal physiology. Pharmacol Rev 2002;54:431-467.

40. Parton RG, Simons K. The multiple faces of caveolae. Nat Rev Mol Cell Biol 2007;8:185-194.

41. Nabi IR. Cavin fever: regulating caveolae. Nat Cell Biol 2009;11: 789-791.

42. Hansen CG, Nichols BJ. Exploring the caves: cavins, caveolins and caveolae. Trends Cell Biol 2010;20:177-186.

43. Hayer A, Stoeber M, Bissig C et al. Biogenesis of caveolae: stepwise assembly of large caveolin and cavin complexes. Traffic 2010;11: 361-382.

44. Briand N, Dugail I, Le Lay S. Cavin proteins: new players in the caveolae field. Biochimie 2011;93:71-77.

45. Drab $M$, Verkade $P$, Elger $M$ et al. Loss of caveolae, vascular dysfunction, and pulmonary defects in caveolin-1 genedisrupted mice. Science 2001;293:2449-2452.

46. Hill MM, Bastiani M, Luetterforst $\mathrm{R}$ et al. PTRF-Cavin, a conserved cytoplasmic protein required for caveola formation and function. Cell 2008;132:113-124.

47. Liu L, Pilch PF. A critical role of cavin (polymerase I and transcript release factor) in caveolae formation and organization. J Biol Chem 2008;283:4314-4322.

48. Liu L, Brown D, McKee M et al. Deletion of Cavin/PTRF causes global loss of caveolae, dyslipidemia, and glucose intolerance. Cell Metab 2008;8:310-317.

49. Fra AM, Williamson $\mathrm{E}$, Simons $\mathrm{K}$ et al. De novo formation of caveolae in lymphocytes by expression of VIP21-caveolin. Proc Natl Acad Sci USA 1995;92:8655-8659.

50. Walser PJ, Ariotti $\mathrm{N}$, Howes $\mathrm{M}$ et al. Constitutive formation of caveolae in a bacterium. Cell 2012;150:752-763.

51. Hansen CG, Shvets E, Howard G et al. Deletion of cavin genes reveals tissue-specific mechanisms for morphogenesis of endothelial caveolae. Nat Commun 2013;4:1831.

52. Rossi S, Poliani PL, Cominelli $\mathrm{M}$ et al. Caveolin 1 is a marker of poor differentiation in rhabdomyosarcoma. Eur J Cancer 2011;47:761-772.

53. Rossi S, Poliani PL, Missale C et al. Caveolins in rhabdomyosarcoma. J Cell Mol Med 2011;15:2553-2568

54. Faggi F, Mitola S, Sorci G et al. Phosphocaveolin-1 enforces tumor growth and chemoresistance in rhabdomyosarcoma. PLoS One 2014;9:e84618.

55. Irizarry RA, Hobbs B, Collin F et al. Exploration, normalization, and summaries of high density oligonucleotide array probe level data. Biostatistics 2003;4:249-264.

56. Madaro L, Marrocco V, Fiore P et al. PKC $\theta$ signaling is required for myoblast fusion by regulating the expression of caveolin-3 and $\beta 1 \mathrm{D}$ integrin upstream focal adhesion kinase. Mol Biol Cell 2011;22: 1409-1419.

57. Houghton JA, Houghton PJ, Brodeur GM et al. Development of resistance to vincristine in a childhood rhabdomyosarcoma growing in immune-deprived mice. Int J Cancer 1981;28:409-415.

58. Stratton MR, Fisher C, Gusterson BA et al. Detection of point mutations in N-ras and K-ras genes of human embryonal rhabdomyosarcomas using oligonucleotide probes and the polymerase chain reaction. Cancer Res 1989;49:6324-6327.

59. Felix CA, Kappel CC, Mitsudomi T et al. Frequency and diversity of $\mathrm{p} 53$ mutations in childhood rhabdomyosarcoma. Cancer Res 1992;52: 2243-2247.

60. Lollini PL, De Giovanni C, Landuzzi L et al. Reduced metastatic ability of in vitro differentiated human rhabdomyosarcoma cells. Invasion Metastasis 1991;11:116-124.

61. Astolfi A, De Giovanni C, Landuzzi L et al. Identification of new genes related to the myogenic differentiation arrest of human rhabdomyosarcoma cells. Gene 2001;274:139-149.

62. Douglass EC, Valentine M, Etcubanas E et al. A specific chromosomal abnormality in rhabdomyosarcoma. Cytogenet Cell Genet 1987;45: 148-155.

63. Borenfreund E, Puerner JA. Toxicity determined in vitro by morphological alterations and neutral red absorption. Toxicol Lett $1985 ; 24: 119-124$ 
64. Repetto G, del Peso A, Zurita JL. Neutral red uptake assay for the estimation of cell viability/cytotoxicity. Nat Protoc 2008;3:1125-1131.

65. Pannérec A, Marazzi G, Sassoon D. Stem cells in the hood: the skeletal muscle niche. Trends Mol Med 2012;18:599-606.

66. Marampon F, Ciccarelli C, Zani BM. Down-regulation of c-Myc following MEK/ERK inhibition halts the expression of malignant phenotype in rhabdomyosarcoma and in non muscle-derived human tumors. Mol Cancer 2006;5:31.

67. Marampon F, Bossi G, Ciccarelli C et al. MEK/ERK inhibitor U0126 affects in vitro and in vivo growth of embryonal rhabdomyosarcoma. Mol Cancer Ther 2009;8:543-551.

68. Dąbroś W, Adamczyk A, Ciurkot K et al. Vanadium compounds affect growth and morphology of human rhabdomyosarcoma cell line. Pol J Pathol 2011;62:262-268.

69. Hayer A, Stoeber M, Ritz D et al. Caveolin-1 is ubiquitinated and targeted to intralumenal vesicles in endolysosomes for degradation. J Cell Biol 2010;191:615-629.

70. Detzer A, Engel $C$, Wünsche $W$ et al. Cell stress is related to relocalization of Argonaute 2 and to decreased RNA interference in human cells. Nucleic Acids Res 2011;39:2727-2741.

71. Jansa P, Mason SW, Hoffmann-Rohrer $U$ et al. Cloning and functional characterization of PTRF, a novel protein which induces dissociation of paused ternary transcription complexes. EMBO J 1998;17:2855-2864.

72. Jansa P, Burek C, Sander EE et al. The transcript release factor PTRF augments ribosomal gene transcription by facilitating reinitiation of RNA polymerase I. Nucleic Acids Res 2001;29:423-429.

73. Hasegawa T, Takeuchi A, Miyaishi $\mathrm{O}$ et al. PTRF (polymerase I and transcript-release factor) is tissue-specific and interacts with the BFCOL1 (binding factor of a type-I collagen promoter) zinc-finger transcription factor which binds to the two mouse type-I collagen gene promoters. Biochem J 2000;347:55-59.

74. Foster $\sqcup$, De Hoog CL, Mann M. Unbiased quantitative proteomics of lipid rafts reveals high specificity for signaling factors. Proc Natl Acad Sci USA 2003;100:5813-5818.

75. Vinten J, Voldstedlund M, Clausen $\mathrm{H}$ et al. A 60-kDa protein abundant in adipocyte caveolae. Cell Tissue Res 2001;305:99-106.

76. Aboulaich $\mathrm{N}$, Vainonen JP, Strålfors $\mathrm{P}$ et al. Vectorial proteomics reveal targeting, phosphorylation and specific fragmentation of polymerase I and transcript release factor (PTRF) at the surface of caveolae in human adipocytes. Biochem J 2004;383:237-248.

77. Aboulaich N, Ortegren U, Vener AV et al. Association and insulin regulated translocation of hormone-sensitive lipase with PTRF. Biochem Biophys Res Commun 2006;350:657-661.

78. Aboulaich N, Chui PC, Asara JM et al. Polymerase I and transcript release factor regulates lipolysis via a phosphorylation-dependent mechanism. Diabetes 2011;60:757-765.

79. Dwianingsih EK, Takeshima $\mathrm{Y}$, Itoh $\mathrm{K}$ et al. A Japanese child with asymptomatic elevation of serum creatine kinase shows PTRF-CAVIN mutation matching with congenital generalized lipodystrophy type 4 . Mol Genet Metab 2010;101:233-237.

80. Hayashi YK, Matsuda C, Ogawa M et al. Human PTRF mutations cause secondary deficiency of caveolins resulting in muscular dystrophy with generalized lipodystrophy. J Clin Invest 2009;119:2623-2633.

81. Rajab A, Straub V, McCann LJ et al. Fatal cardiac arrhythmia and longQT syndrome in a new form of congenital generalized lipodystrophy with muscle rippling (CGL4) due to PTRF-CAVIN mutations. PLoS Genet 2010;6:e1000874.

82. Shastry S, Delgado MR, Dirik E et al. Congenital generalized lipodystrophy, type 4 (CGL4) associated with myopathy due to novel PTRF mutations. Am J Med Genet A 2010;152A:2245-2253.

83. Ardissone A, Bragato C, Caffi L et al. Novel PTRF mutation in a child with mild myopathy and very mild congenital lipodystrophy. BMC Med Genet 2013;14:89.
84. de Haan W. Lipodystrophy and muscular dystrophy caused by PTRF mutations. Clin Genet 2010;77:436-437.

85. Ding SY, Lee MJ, Summer R et al. Pleiotropic effects of cavin-1 deficiency on lipid metabolism. J Biol Chem 2014;289:8473-8483.

86. Zhu H, Lin P, De G et al. Polymerase transcriptase release factor (PTRF) anchors MG53 protein to cell injury site for initiation of membrane repair. J Biol Chem 2011;286:12820-12824.

87. Bai L, Deng X, Li Q et al. Down-regulation of the cavin family proteins in breast cancer. J Cell Biochem 2012;113:322-328.

88. Gámez-Pozo A, Sánchez-Navarro I, Calvo E et al. PTRF/cavin-1 and MIF proteins are identified as non-small cell lung cancer biomarkers by label-free proteomics. PLoS One 2012;7:e33752.

89. Aung CS, Hill MM, Bastiani M et al. PTRF-cavin-1 expression decreases the migration of $\mathrm{PC} 3$ prostate cancer cells: role of matrix metalloprotease 9. Eur J Cell Biol 2011;90:136-142.

90. Hill MM, Daud NH, Aung CS et al. Co-regulation of cell polarization and migration by caveolar proteins PTRF/Cavin-1 and caveolin-1. PLoS One 2012;7:e43041.

91. Inder $\mathrm{KL}$, Zheng $\mathrm{YZ}$, Davis $\mathrm{MJ}$ et al. Expression of PTRF in PC-3 cells modulates cholesterol dynamics and the actin cytoskeleton impacting secretion pathways. Mol Cell Proteomics 2012;11:M111.012245.

92. Moon $\mathrm{H}$, Lee CS, Inder KL et al. PTRF/cavin-1 neutralizes non-caveolar caveolin-1 microdomains in prostate cancer. Oncogene 2014;33: 3561-3570.

93. Nassar ZD, Moon H, Duong T et al. PTRF/Cavin-1 decreases prostate cancer angiogenesis and lymphangiogenesis. Oncotarget 2013;4: 1844-1855.

94. Liu L, Xu HX, Wang WQ et al. Cavin-1 is essential for the tumorpromoting effect of caveolin-1 and enhances its prognostic potency in pancreatic cancer. Oncogene 2013;33:2728-2736.

95. Yi JS, Mun DG, Lee $\mathrm{H}$ et al. PTRF/Cavin-1 is essential for multidrug resistance in cancer cells. J Proteome Res 2013;12:605-614.

96. Williams TM, Lisanti MP. Caveolin-1 in oncogenic transformation, cancer, and metastasis. Am J Physiol Cell Physiol 2005;288: C494-C506.

97. Burgermeister $\mathrm{E}$, Liscovitch $\mathrm{M}$, Röcken $\mathrm{C}$ et al. Caveats of caveolin-1 in cancer progression. Cancer Lett 2008;268:187-201.

98. Goetz JG, Lajoie P, Wiseman SM et al. Caveolin-1 in tumor progression: the good, the bad and the ugly. Cancer Metastasis Rev 2008;27:715-735

99. Sáinz-Jaspeado M, Martin-Liberal J, Lagares-Tena L et al. Caveolin-1 in sarcomas: friend or foe? Oncotarget 2011;2:305-312.

100. Tirado OM, MacCarthy CM, Fatima $\mathrm{N}$ et al. Caveolin-1 promotes resistance to chemotherapy-induced apoptosis in Ewing's sarcoma cells by modulating PKCalpha phosphorylation. Int J Cancer 2010;126: 426-436.

101. Gupta R, Toufaily C, Annabi B. Caveolin and cavin family members: dual roles in cancer. Biochimie 2014;107:188-202.

102. Volonte D, Galbiati F. Polymerase I and transcript release factor (PTRF)/cavin-1 is a novel regulator of stress-induced premature senescence. J Biol Chem 2011;286:28657-28661.

103. Bai L, Deng X, Li J et al. Regulation of cellular senescence by the essential caveolar component PTRF/Cavin-1. Cell Res 2011;21: 1088-1101.

104. Salani B, Passalacqua $M$, Maffioli $S$ et al. IGF-IR internalizes with Caveolin-1 and PTRF/Cavin in HaCat cells. PLoS One 2010;5: e14157.

105. Hamoudane M, Maffioli S, Cordera R et al. Caveolin-1 and polymerase I and transcript release factor: new players in insulin-like growth factor-I receptor signaling. J Endocrinol Invest 2013;36:204-208.

106. Malkin D, Li FP, Strong LC et al. Germ line p53 mutations in a familial syndrome of breast cancer, sarcomas, and other neoplasms. Science 1990:250:1233-1238. 